\title{
Lack of $\mathrm{CD}^{+}$T-cell co-localization with Kaposi's sarcoma- associated herpesvirus infected cells in Kaposi's sarcoma tumors
}

\author{
Salum J. Lidenge ${ }^{1,2,4,5}$, For Yue Tso ${ }^{1,2}$, Owen Ngalamika ${ }^{6}$, Jaydeep Kolape ${ }^{7}$ John R. \\ Ngowi $^{4}$, Julius Mwaiselage ${ }^{4,5}$, Charles Wood ${ }^{1,2,3}$ and John T. West ${ }^{1,3}$ \\ ${ }^{1}$ Nebraska Center for Virology, Lincoln, NE, USA \\ ${ }^{2}$ School of Biological Sciences, University of Nebraska-Lincoln, Lincoln, NE, USA \\ ${ }^{3}$ Department of Biochemistry, University of Nebraska-Lincoln, Lincoln, NE, USA \\ ${ }^{4}$ Ocean Road Cancer Institute, Dar es Salaam, Tanzania \\ ${ }^{5}$ Muhimbili University of Health and Allied Sciences, Dar es Salaam, Tanzania \\ ${ }^{6}$ Dermatology and Venereology Section, University Teaching Hospitals, University of Zambia School of Medicine, Lusaka, \\ Zambia \\ ${ }^{7}$ Morrison Microscopy Core Facility, Center for Biotechnology, University of Nebraska-Lincoln, Lincoln, NE, USA \\ Correspondence to: John T. West, email: jwest2@unl.edu \\ Keywords: Kaposi's sarcoma; HIV-1; KSHV; immune cells; tumor microenvironment \\ Received: February 18, $2020 \quad$ Accepted: April 03, $2020 \quad$ Published: April 28, 2020
}

Copyright: Lidenge et al. This is an open-access article distributed under the terms of the Creative Commons Attribution License 3.0 (CC BY 3.0), which permits unrestricted use, distribution, and reproduction in any medium, provided the original author and source are credited.

\section{ABSTRACT}

Despite the close association between Kaposi's sarcoma (KS) and immune dysfunction, it remains unclear whether tumor infiltrating immune cells (TIIC), by their absence, presence, or dysfunction, are mechanistically correlated with KS pathogenesis. Therefore, their potential capacity to serve as prognostic biomarkers of KS disease progression or control is unclear. Because epidemic-KS (EpKS) occurs with HIV-1 co-infection, it is particularly important to compare TIIC between EpKS and HIV-negative African endemic-KS (EnKS) to dissect the roles of HIV-1 and Kaposi Sarcoma-associated herpesvirus (KSHV) in KS pathogenesis. This cross-sectional study of 13 advanced KS (4 EnKS, 9 EpKS) patients and 3 healthy controls utilized single-color immunohistochemistry and dual-color immunofluorescence assays to characterize and quantify KSHV infected cells in relation to various TIIC in KS biopsies. Analysis of variance (ANOVA) and Mann-Whitney tests were used to assess differences between groups where $P$-values $<0.05$ were considered significant. The abundance of KSHV infected cells was heterogeneous in KS biopsies. Despite the presence of $T$-cell chemoattractant chemokine CxCL-9 in biopsies, $\mathrm{CD8}^{+} \mathrm{T}$-cells were sparsely distributed in regions with evident KSHV infected cells but were readily detectable in regions devoid of KSHV infected cells $(P<0.0001) . \mathrm{CD}^{+}(\mathrm{M1})$ macrophages were evenly and diffusely distributed in KS biopsies, whereas, the majority of $\mathrm{CD}_{163^{+}}$(M2) macrophages were localized in regions devoid of KSHV infected cells $(P<\mathbf{0 . 0 0 0 1})$. Overall, the poor immune cell infiltration or co-localization in KS biopsies independent of HIV-1 co-infection suggests a fundamental tumor immune evasion mechanism that warrants further investigation.

\section{INTRODUCTION}

Increased incidence of Kaposi's sarcoma (KS) in the HIV-1 infected (EpKS), transplant recipients, and in the elderly, implies that immune dysregulation or immune suppression plays a role in tumorigenesis [1, 2]. However, the precise nature of this dysregulation and how it drives KS remains poorly understood. Pathogenetic mechanisms driving African endemic-KS (EnKS), which is responsible for an estimated $4-10 \%$ of African adult cancers [3, 4], are even less clear, since EnKS occurs in both genders as well as children and in the absence of HIV-1 infection or other 
known immune dysfunctions. Indeed we have shown that KSHV viremia and humoral responses in EnKS show few significant differentials in comparison to those in EpKS [5].

Tumor infiltrating immune cells (TIIC) are indicators of tumor-related immune responses and are therefore often the targets of cancer immunotherapy [6]. For example, $\mathrm{CD} 8^{+} \mathrm{T}$-cell infiltration in lung cancer and melanomas has been used as prognostic tool $[7,8]$. In addition, tumor infiltration of myeloid lineage cells with a pro-inflammatory macrophage phenotype is also associated with tumor prognosis. Pro-inflammatory (M1) macrophages promote cytotoxic and anti-tumor CD8 and CD4 responses, whereas anti-inflammatory M2 macrophages contribute to Th2 responses, tissues repair and tumor growth [9-11]. Promoting a switch from the M2 to M1 phenotype in tumors and induction of proinflammatory cytotoxic T-cell responses has also been shown to slow or stop cancer growth [12]. Therapeutically, isolation of TIIC, such as T-cells, from tumors, followed by ex vivo expansion, antigenic stimulation and transfer back to the same patient is now a viable treatment strategy in cancers like melanoma and cervical carcinoma $[13,14]$. Defining the value of TIIC as cancer prognostic marker is therefore an active area of research for a number of human cancers $[7,15,16]$. Nevertheless, despite the close association between $\mathrm{KS}$ and immune dysfunction [5], it remains unclear whether TIIC are a critical component in KS pathogenesis, and whether their absence, presence, or dysregulation could serve as a prognostic biomarker of KS disease progression or control. This is particularly relevant for comparison of EpKS to EnKS where the disease presentation, pathology and humoral immune parameters appear to be highly similar and therefore, the direct or indirect role of HIV-1 in KS remains unclear [5].

Our recent transcriptomic comparison of KS lesions to normal skin from the same individuals, revealed that KS lesions exhibited elevated expression of CxCL-9, CXCL10 and CXCL-11 [17]. Since these chemokines are known to create chemotactic gradients for T-cell recruitment to sites of infection or loss of homeostasis [18], we asked whether CxCL-9 transcript upregulation was also evident at the protein levels in KS lesions, and if such over-expression correlated with immune cell infiltration into the KS microenvironment. Additionally, because transcriptomics revealed little or no HIV-1 transcription in EpKS lesions (16), we sought to investigate potential indirect effects of HIV-1 immune dysregulation in KS, through comparison of immune cell infiltration between EpKS and EnKS patients. We biopsied EpKS and EnKS patients from sub-Saharan Africa (SSA) to explore the relationships between chemokine expression, Kaposi's sarcoma-associated herpesvirus (KSHV)-infected cells, TIIC and HIV-1 co-infection. Our study reveals poor immune cell infiltration in most KS tissues and lack of colocalization between TIIC and regions with demonstrable
KSHV infection but detected no differentials in immune cell infiltration as a result of HIV-1 co-infection.

\section{RESULTS}

\section{Characteristics of study subjects}

To investigate the relationship between KSHV infected cells and TIIC in KS biopsies, samples with LANA+ cells demonstrable by IHC were utilized. A total of $13 \mathrm{KS}$ cases (4 EnKS and 9 EpKS) and 3 normal skin donors were evaluated for this study. Ages in the cohort ranged from 27 to 84 with a median of 42 years (Table 1). The self-reported duration of KS ranged from 2 months to 3 years at the time of recruitment and was similar between EnKS and EpKS at a median of 6 and 3 months, respectively. EpKS patients were all ART experienced with undetectable plasma HIV-1 load, excepting patient C038 and 21242 who were on ART for less than a month and patient $\mathrm{C} 3097$ who was experiencing ART failure. Consistent with the most common presentation of KS in the region [19], most patients had nodular morphotype KS lesions on the extremities (Table 1).

\section{Heterogeneous expression of LANA in KS biopsies}

To investigate the relationships between KSHV infected cells and TIIC, we first defined 'infected cells' as those evincing a punctate nuclear KSHV LANA staining pattern by IHC [20]. LANA is responsible for maintaining the KSHV episome in infected cells during latency and is also expressed in lytic reactivation [21]. In all KS biopsies, characteristic spindle-morphology cells were evident throughout the biopsy; however, we observed heterogeneous distributions of $\mathrm{LANA}^{+}$cells. While LANA was not detectable in all spindle cells, some biopsies had a high abundance of $\mathrm{LANA}^{+}$cells. KS biopsies with medium and low frequency $\mathrm{LANA}^{+}$cell distributions were also common (Figure 1A).

\section{LANA+ cells in KS biopsies express endothelial cells marker}

Studies have suggested that the majority of KSHV infected cells in tumors express markers of endothelial cell lineage including CD34 $[22,23]$. To confirm the endothelial lineage of KSHV infected cells in the biopsies studied, we utilized DIF staining to simultaneously detect LANA in the nuclei and CD34 on the cell surface. We found that majority of the $\mathrm{LANA}^{+}$cells in KS biopsies were $\mathrm{CD} 34+$ and thus appear to be of endothelial origin, whereas in normal skin, the CD34+ cells were confined to distinct vasculature and LANA was absent. Interestingly, although the majority of $\mathrm{LANA}^{+}$cells appeared to be endothelial in origin, there were some CD34 negative 
Table 1: Characteristics of study subjects

\begin{tabular}{|c|c|c|c|c|c|c|c|c|}
\hline ID & Gender & Age & HIV-1 Status & KS Duration ${ }^{* *}$ & $\begin{array}{c}\text { ART } \\
\text { Duration }\end{array}$ & $\begin{array}{c}\text { Plasma HIV- } \\
1 \text { load }^{*}\end{array}$ & $\begin{array}{c}\text { Lesion } \\
\text { Type }\end{array}$ & Lesion Site \\
\hline C3096 & $\mathrm{M}$ & 27 & - & 3 months & NA & NA & Nodular & L. Limb \\
\hline C3107 & M & 84 & - & 2 years & NA & NA & Nodular & U. Limb \\
\hline C3138 & M & 72 & - & NR & NA & NA & Nodular & L. Limb \\
\hline $\mathrm{C063}$ & M & 58 & - & 6 months & NA & NA & Nodular & L. Limb \\
\hline C3057 & $\mathrm{F}$ & 37 & + & 3 months & 1 month & $<50$ & Plaque & L. Limb \\
\hline C3094 & M & 45 & + & 2 months & 2 years & $<50$ & Nodular & L. Limb \\
\hline C3097 & $\mathrm{F}$ & 37 & + & 4 months & 7 years & $1.4 \mathrm{E}+06$ & Nodular & L. Limb \\
\hline C3104 & $\mathrm{F}$ & 39 & + & 2 months & 2 months & $<50$ & Nodular & L. Limb \\
\hline C216 & $\mathrm{F}$ & 61 & + & 5 months & 6 months & NR & Nodular & L. Limb \\
\hline C038 & $\mathrm{F}$ & 44 & + & 3 months & 2 days & $1.5 \mathrm{E}+04$ & Nodular & Face \\
\hline 21227 & M & 40 & + & 2 months & 3 months & $<50$ & Plaque & L. Limb \\
\hline 21230 & M & 34 & + & 3 years & 3 years & $<50$ & Nodular & L. Limb \\
\hline 21242 & M & 44 & + & 3 months & 21 days & $3.2 \mathrm{E}+05$ & Nodular & L. Limb \\
\hline 21650 & M & 42 & - & & & Normal Skin & & \\
\hline 21651 & M & 42 & - & & & Normal Skin & & \\
\hline 21652 & $\mathrm{~F}$ & 38 & - & & & Normal Skin & & \\
\hline
\end{tabular}

"copies/mL, ${ }^{* *}$ Self-reported KS duration, L - Lower, U - Upper, NR - Not Recorded, NA - Not Applicable.

but $\mathrm{LANA}^{+}$cells, indicating that other cell types such as fibroblast, epithelial, dendritic and B cells demonstrated to support KSHV infection in vitro may also be present in KS tissues in vivo (Figure 1B) [24-26].

\section{KS tissues express chemoattractant CxCL-9}

Chemokines create chemotactic gradients that can recruit immune cells to the sites of an infection or neoplasia [18]. Expression of T-cell chemoattractants in tissue could suggest an attempt to recruit T-cells to tissue sites. Alternately, these types of chemokines are often produced by myeloid cells that have polarized phenotypes that could be either cancer supportive, cancer repressive or neither. Our recent comparative transcriptomics analysis of KS biopsies versus ipsilateral/contralateral normal skin from the same individual demonstrated that KS lesions express significantly high levels of T-cell chemoattractants CxCL-9, 10 and 11 compared to normal skin [17]. CxCL-9 was examined instead of CxCL-10 and -11 because it was upregulated the most in KS lesions vs controls skin at false discovery rate (FDR) $<5 \%$ [17]. Using DIF co-staining for LANA and CxCL-9, we found that CxCL-9 was indeed expressed at higher levels in both EpKS and EnKS tissue compared to normal skin, consistent with our published transcriptomics analysis [17] (Figure 2). Most CxCL-9 positive cells in KS tissue were LANA ${ }^{-}$and localized in areas with reduced or undetectable LANA expression. Overall, this suggests that T-cell recruitment into KS is not localized to the KSHV infected regions of both EpKS and EnKS tissues.

\section{Lack of $\mathrm{CD8}^{+}$T-cells co-localization with LANA- expressing cells in KS tissues}

Cytotoxic T-cells are anticipated to migrate into areas of foreign/tumor antigens in response to chemokines, such as CxCL-9 [27, 28]. To investigate $\mathrm{CD}^{+}$T-cell infiltration, adjacent tissues sections were IHC stained for LANA and CD8 expression, respectively. Regions with high numbers of $\mathrm{LANA}^{+}$cells and high CD8 ${ }^{+} \mathrm{T}$-cells on the adjacent slides were identified and statistically compared (Figure 3A). Overall, there were more CD8 ${ }^{+}$ T-cells in KS tissue sections compared to normal skin. There was a lack of co-localization of cells with LANA signal and $\mathrm{CD} 8^{+} \mathrm{T}$-cells on the adjacent section from the same tissue biopsy in 12 out of 13 analyzed KS tissues. Although CD8+ T-cells were present, but they were sparsely distributed within $\mathrm{LANA}^{+}$regions of both EpKS and EnKS tissues (Figure 3A), with the majority found in regions devoid of LANA $(P<0.0001)$ (Figure 3B). These results were validated with identical findings using a different source of anti-CD8 antibody (Supplementary Figure 1).

The use of adjacent tissues sections with traditional single-color IHC to infer co-localization of markers is challenging, as two sequential sections need to be overlaid to determine co-localization. In order to solve this challenge and re-examine the relationship between infected cells and TIIC, we further utilized DIF to stain for LANA and $\mathrm{CD} 8^{+}$T-cells on the same tissue section. Consistent with the IHC results, there was a lack of colocalization of $\mathrm{LANA}^{+}$cells and $\mathrm{CD} 8^{+} \mathrm{T}$-cells on the same 
section (Figure 4A). While $\mathrm{CD}^{+}$T-cells were detectable in $\mathrm{LANA}^{+}$regions of the tissues, their distribution was sparse and less abundant compared to regions devoid of LANA $(P<0.0001)$ (Figure 4B). Importantly, the proportions of $\mathrm{CD}^{+}$T-cells in $\mathrm{LANA}^{+}$regions were similar to proportions in normal skin for most tumor biopsies (Supplementary Figure 2). However, CD4 ${ }^{+}$ (Helper T-cells), CD19+ (B-cells) and CD56 ${ }^{+}$(NK cells) cells were nearly absent in most KS tissues, and when present, were at levels indistinguishable from levels in normal skin tissue (data not shown). Overall, there was lack of co-localization of $\mathrm{CD}^{+}, \mathrm{CD}^{+}, \mathrm{B}$, or NK cells in the vicinity of KSHV infected cells.

To investigate the potential impact of HIV-1 co-infection on TIIC infiltration into KS tissues, we compared staining for CD8, CD4, B, and NK cells between EpKS and EnKS patients. The dearth of $\mathrm{CD}^{+}$ $\mathrm{T}$-cell infiltration into $\mathrm{LANA}^{+}$regions of $\mathrm{KS}$ biopsies in
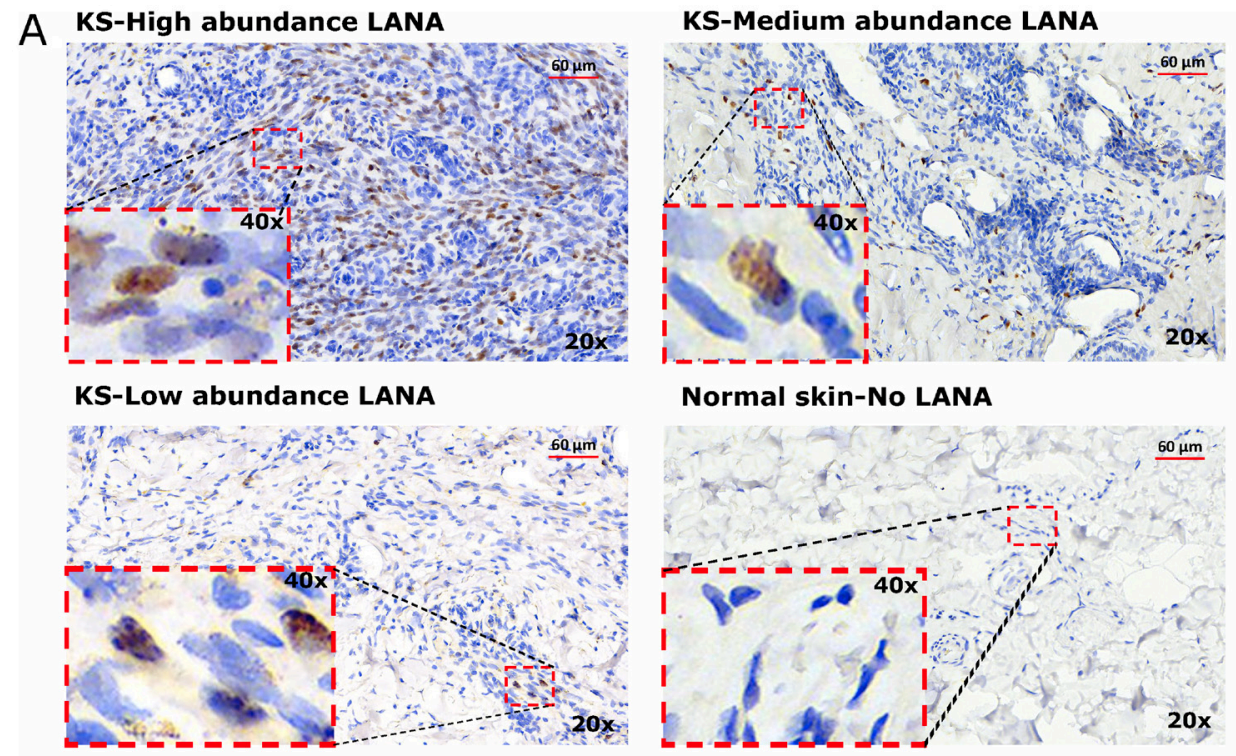

\section{Normal skin-No LANA}
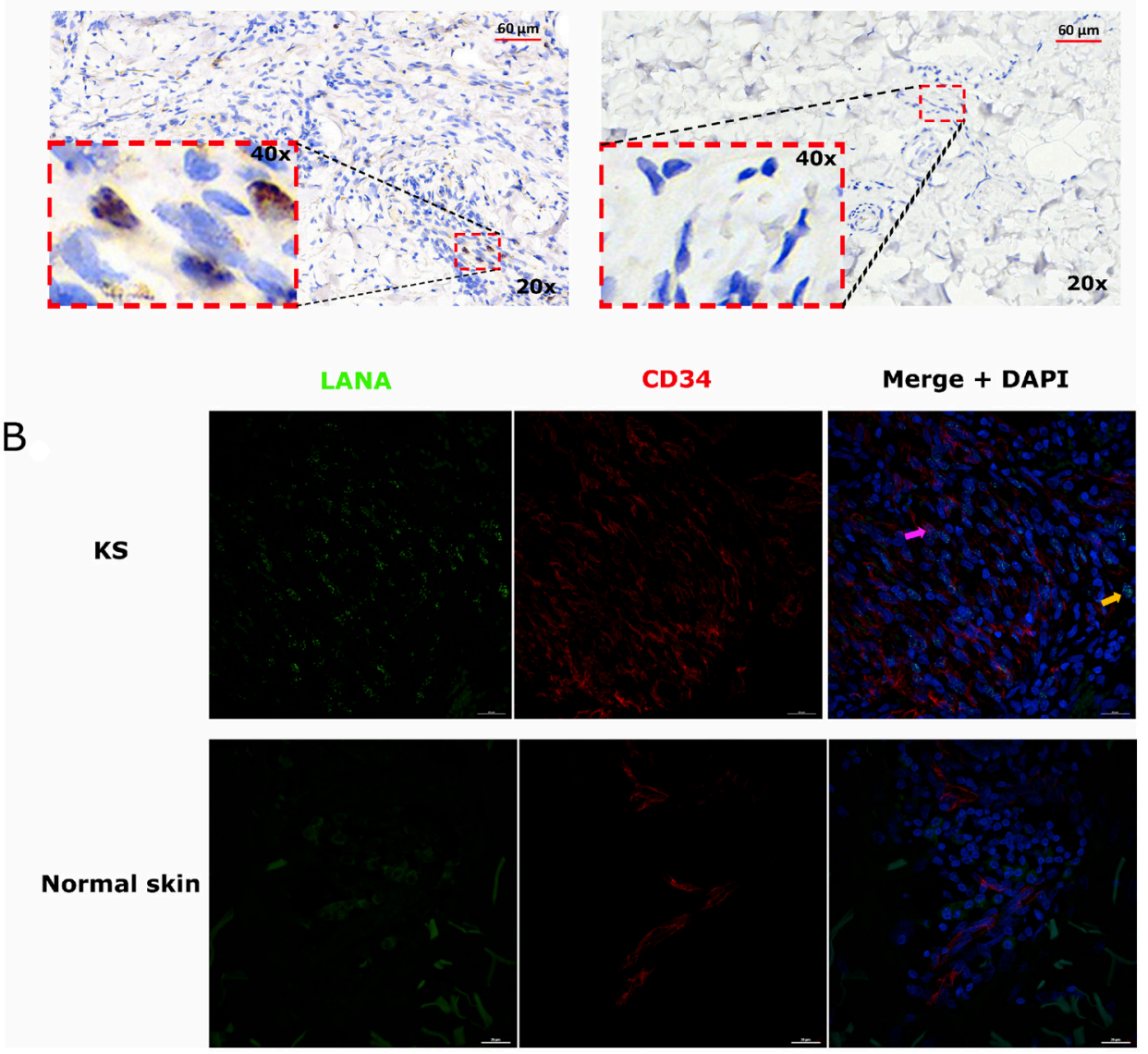

Figure 1: (A) Representative images showing varying abundancies of Kaposi's Sarcoma-associated Herpesvirus (KSHV) Latency Associated Nuclear Antigen (LANA) protein on Kaposi's Sarcoma (KS) tissues and normal skin by immunohistochemistry (IHC) staining. Representative images at 20× and 40× magnification are shown for KS tissue with high abundance LANA positive cells ID-21242, medium abundance LANA positive cells ID-21230, low abundance LANA positive cells ID-21229 and normal skin with no LANA positive cells IDC063-control. (B) Dual-immunofluorescence staining of Kaposi's Sarcoma-associated Herpesvirus (KSHV) Latency Associated Nuclear Antigen (LANA) protein and endothelial cell surface marker CD34 on Kaposi's Sarcoma (KS) tissues ID-C3096 and normal skin ID21650. Representative images are shown, Alexa 488 (green) for LANA, Alexa 647 (red) for CD34 and 4',6-Diamino-2-Phenylindole, Dihydrochloride (DAPI) (blue) for nuclei staining. Pink arrow - LANA positive and CD34 positive cell, Orange arrow - LANA positive and CD34 negative cell. 
EpKS was comparable to EnKS (Figure 5) and revealed no differences in the infiltration or co-localization of lymphocytes upon HIV-1 co-infection. Similarly, CD4 T-cells, B, and NK cells were not differential between EpKS and EnKS patients.

\section{CD163 expressing cells are in LANA negative region}

Tissue resident or infiltrating macrophages can produce chemokines, including $\mathrm{CxCL}-9$, to recruit T-cells to areas with antigens [29]. However, in the tumor microenvironment, macrophages are also known to produce inflammatory mediators and reactive oxygen species that can induce angiogenesis and promote tumor progression [30-32]. To investigate the M2/antiinflammatory macrophage distribution in KS tissues, we evaluated the distribution of CD163, a hemoglobinhaptoglobin acute phase marker which is often correlated with myeloid suppressor phenotypes [33]. While CD163+ myeloid cells were evident in biopsied tissue, the majority were localized in $\mathrm{LANA}^{-}$regions $(P=0.0002)$ (Figure $6 \mathrm{~A}$ and $6 \mathrm{~B})$. Interestingly, while there were less CD163 ${ }^{+}$ cells in $\mathrm{LANA}^{+}$regions than other regions for most $\mathrm{KS}$ tissues, the number of $\mathrm{CD} 63^{+}$cells in $\mathrm{LANA}^{+}$regions were significantly higher in EpKS than in EnKS $(P=$ 0.03 ) (Figure 7A and 7B). This is consistent with increased CD163 levels of expression by the macrophages in HIV1 infection [34, 35]. However, CD163 expression in biopsy tissue was not different between HIV-1 viremic and aviremic EpKS subjects suggesting that ART is not mitigating the impact of HIV-1 on CD163 upregulation (data not shown). We also evaluated the distribution of lectin/selectin-binding scavenger receptor, CD68 as a marker of infiltration of KS tissue by M1/inflammatory macrophages. Cells expressing CD68 were randomly distributed in KS tissues and were not significantly different between $\mathrm{LANA}^{+}$or LANA- regions (Figure 8). Likewise, no differences between EnKS and EpKS in $\mathrm{CD} 8^{+}$cell distribution was evident (Figure 9). However, the ratio of CD68 to CD163 cells was significantly higher in $\mathrm{LANA}^{+}$regions compared to $\mathrm{LANA}^{-}$regions

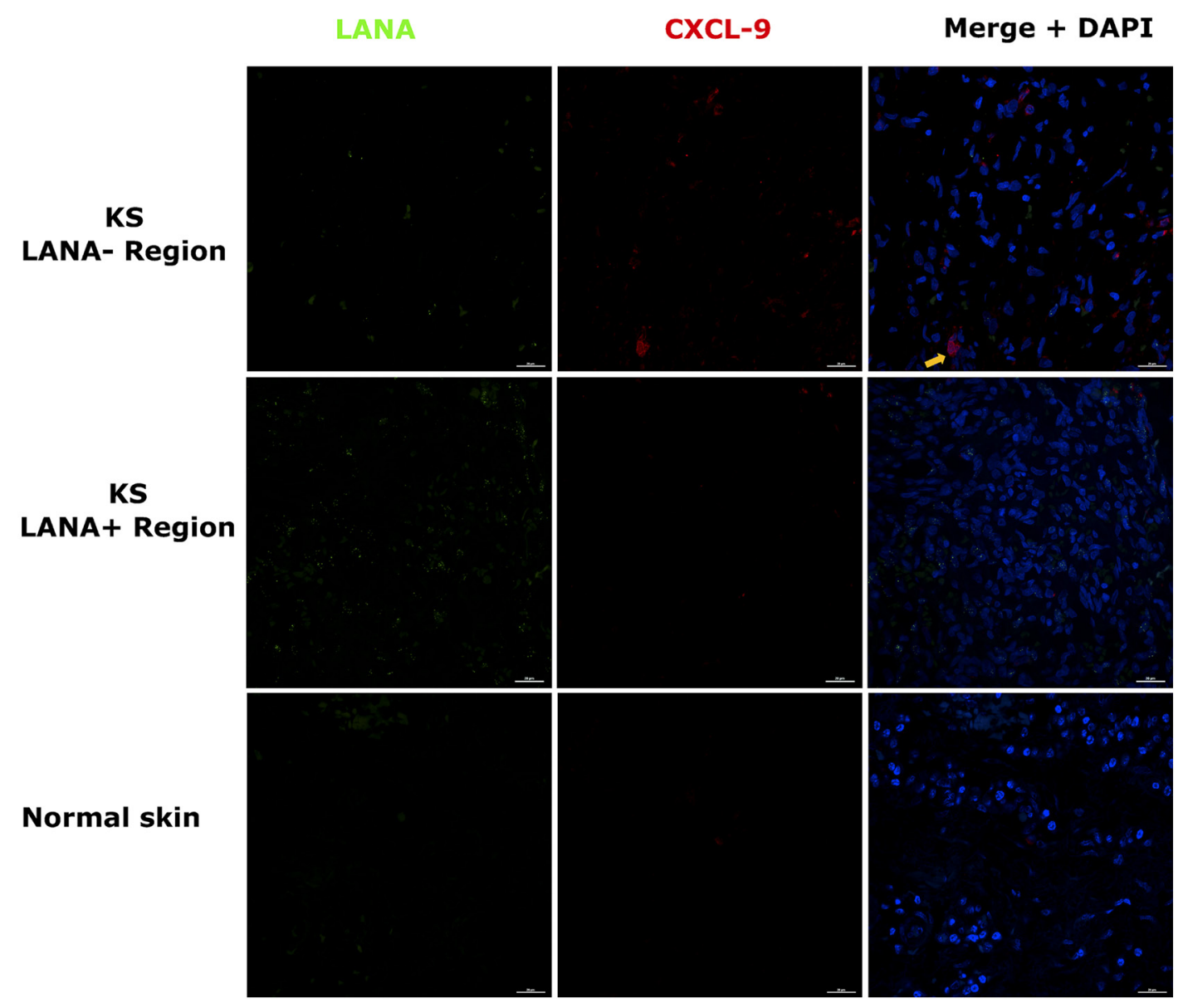

Figure 2: Dual-immunofluorescence staining of Kaposi's sarcoma-associated Herpesvirus (KSHV) Latency Associated Nuclear Antigen (LANA) protein and C-X-C Motif Chemokine Ligand 9 (CxCL-9) on Kaposi's Sarcoma (KS) tissues ID-C3057 (LANA+ and LANA- regions) and normal skin ID-21650. Representative images are shown, Alexa 488 (green) for LANA, Alexa 647 (red) for CxCL-9 and 4',6-Diamino-2-Phenylindole, Dihydrochloride (DAPI) (blue) for nuclei staining. Orange arrow - CxCL-9 positive cell. 
of KS biopsies (Figure 10). Taken together, macrophages in KS tissues do not specifically localize with or target the KSHV infected cells. Moreover, the distribution of myeloid/macrophage cells in KS does not appear to reflect HIV-1 co-infection status or control of HIV-1 viremia.

\section{DISCUSSION}

This is the first study to investigate spatial relationships between chemokine expression, immune cell infiltration and KSHV infected cells in EpKS and EnKS tumor tissues from SSA. Our analysis found that in both EpKS and EnKS, the abundance and distribution of $\mathrm{LANA}^{+}$cells varies widely between $\mathrm{KS}$ biopsies even though most of the patients in this cohort had nodular KS lesions. Consistent with expression of the known T-cell chemoattractant, CxCL-9, in the KS tissues, there were more $\mathrm{CD}^{+} \mathrm{T}$-cells in $\mathrm{KS}$ tissue sections compared to normal skin; however, it was notable that those T-cells did not co-localize with KSHV infected cells.

$\mathrm{CD}^{+}$T-cells play a major role in tumor and intracellular infection control through their capacity to kill infected or cancer cells in response to recognition of class I presented peptides indicative of loss of cellular homeostasis [36]. Immunosuppression induced by the tumor microenvironment can lead to dysfunctional $\mathrm{CD}^{+}$ T-cells and tumor progression [37]. In solid tumors, $\mathrm{CD}^{+}$ T-cell-mediated antitumor activity can be hindered by inhibitory cytokines, altered metabolism, expression of immune checkpoint molecules, abnormal tumor
A

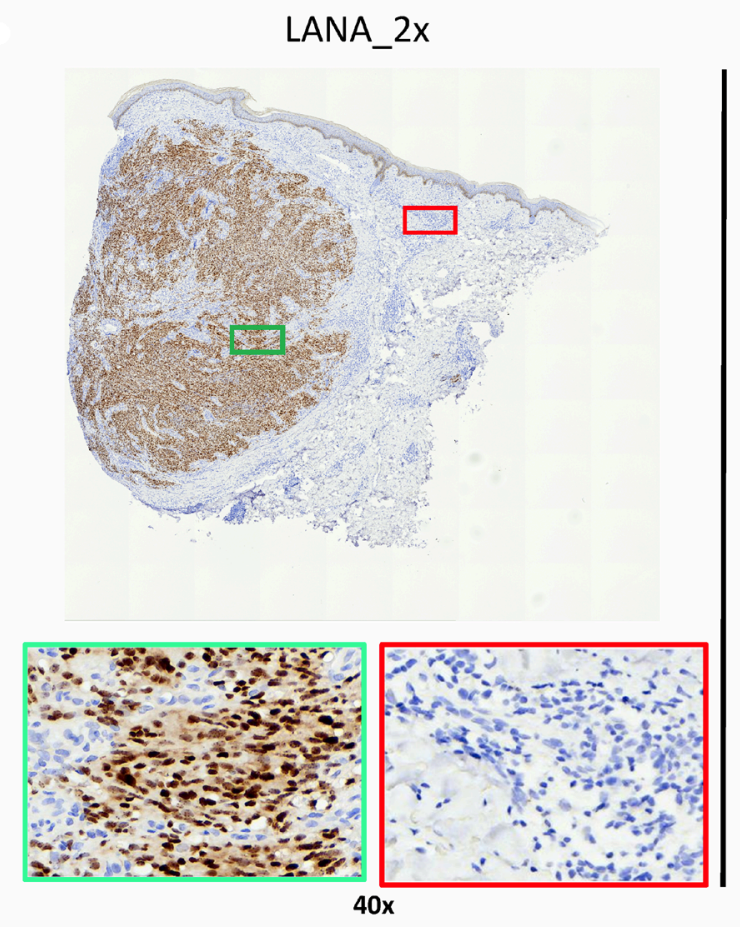

CD8_2x

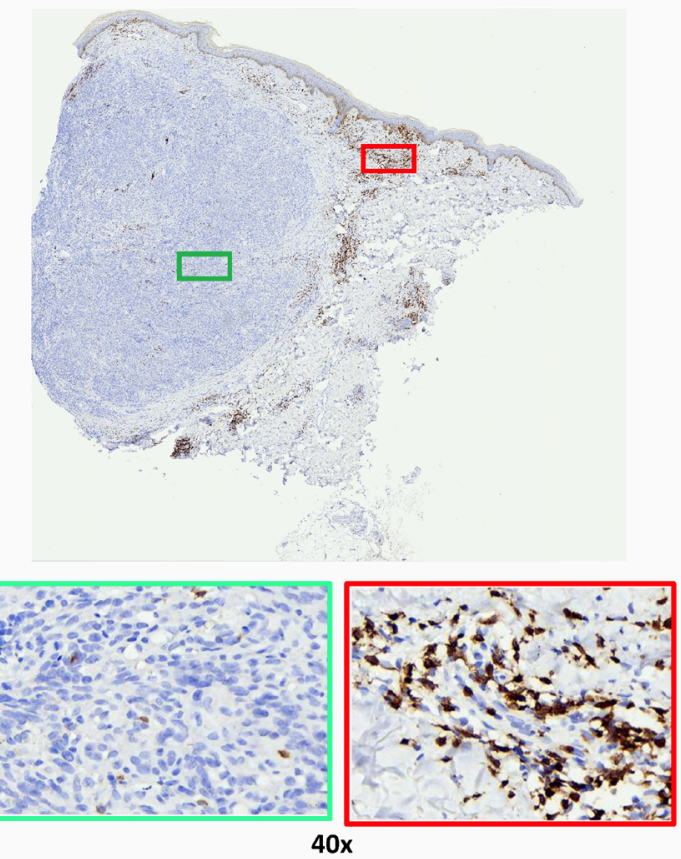

B
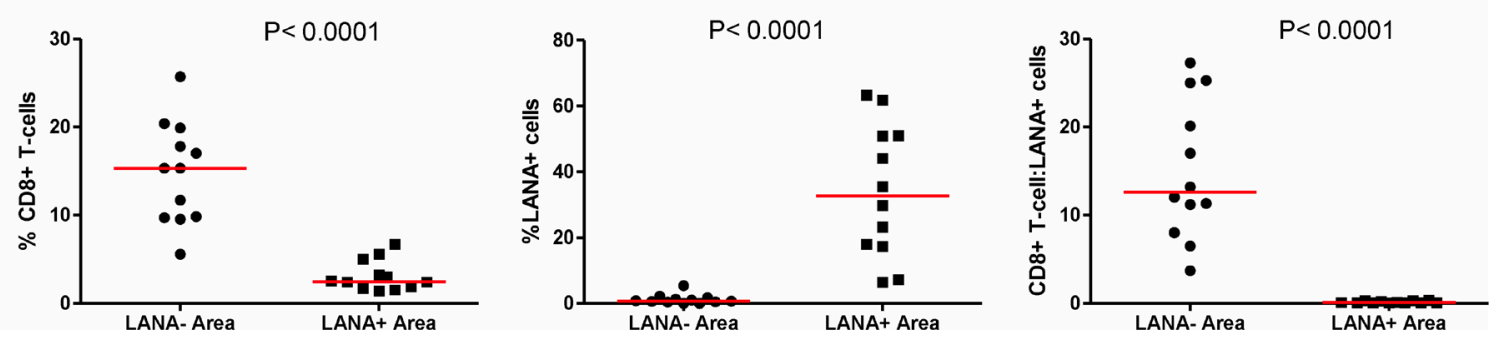

Figure 3: Single-color immunohistochemical staining of adjacent KS tissue sections using mouse anti-LANA and mouse anti-humanCD8 antibodies. (A) Representative scanned images at $2 \times$ and $40 \times$ magnification for LANA and CD8 staining ID-C3097. Green rectangle - LANA positive region of the tissue section, red rectangle - CD8 ${ }^{+}$T-cell region of the tissue section. (B) Quantification plots in LANA+ and $\mathrm{CD}^{+}$regions of the adjacent tissues sections. 
angiogenesis, myelosuppressive cells or regulatory T-cells (Tregs), acting alone or in combination $[37,38]$. In KS, Tregs have been suggested to regulate $\mathrm{CD} 8^{+} \mathrm{T}$-cells [39]. To evaluate which of these potential mechanisms might be contributory to KS pathogenesis, we have initially evaluated markers and cell types that were found to be elevated in our $\mathrm{KS}$ transcriptomics analysis that compared KS tissue to contralateral skin from the same subjects [17]. That study suggested over-expression of T-cell chemoattractant genes and those indicative of immune cell infiltration coupled to a Warburg-like metabolic pattern. Quantification of the extent of $\mathrm{CD}^{+} \mathrm{T}$-cell infiltration into KS tissues revealed a distribution that was limited mainly to areas devoid of KSHV LANA ${ }^{+}$cells. This was surprising, since the T-cell chemoattractant, CxCL-9, was demonstrated to be elevated at the protein level in $\mathrm{KS}$ tissues sections compared to normal skin. Importantly, other T-cell chemoattractants, CxCL-10 and 11 transcripts were also overexpressed in $\mathrm{KS}$ lesions compared to controls [17], but we have not yet attempted detection of those proteins in tissue. While $\mathrm{CD}^{+} \mathrm{T}$-cells were clearly present in the vicinity of KS tumor tissue in excess of the numbers in normal skin, it is possible that recruited $\mathrm{CD}^{+}$ T-cells undergo inhibition from exposure to the cytokines
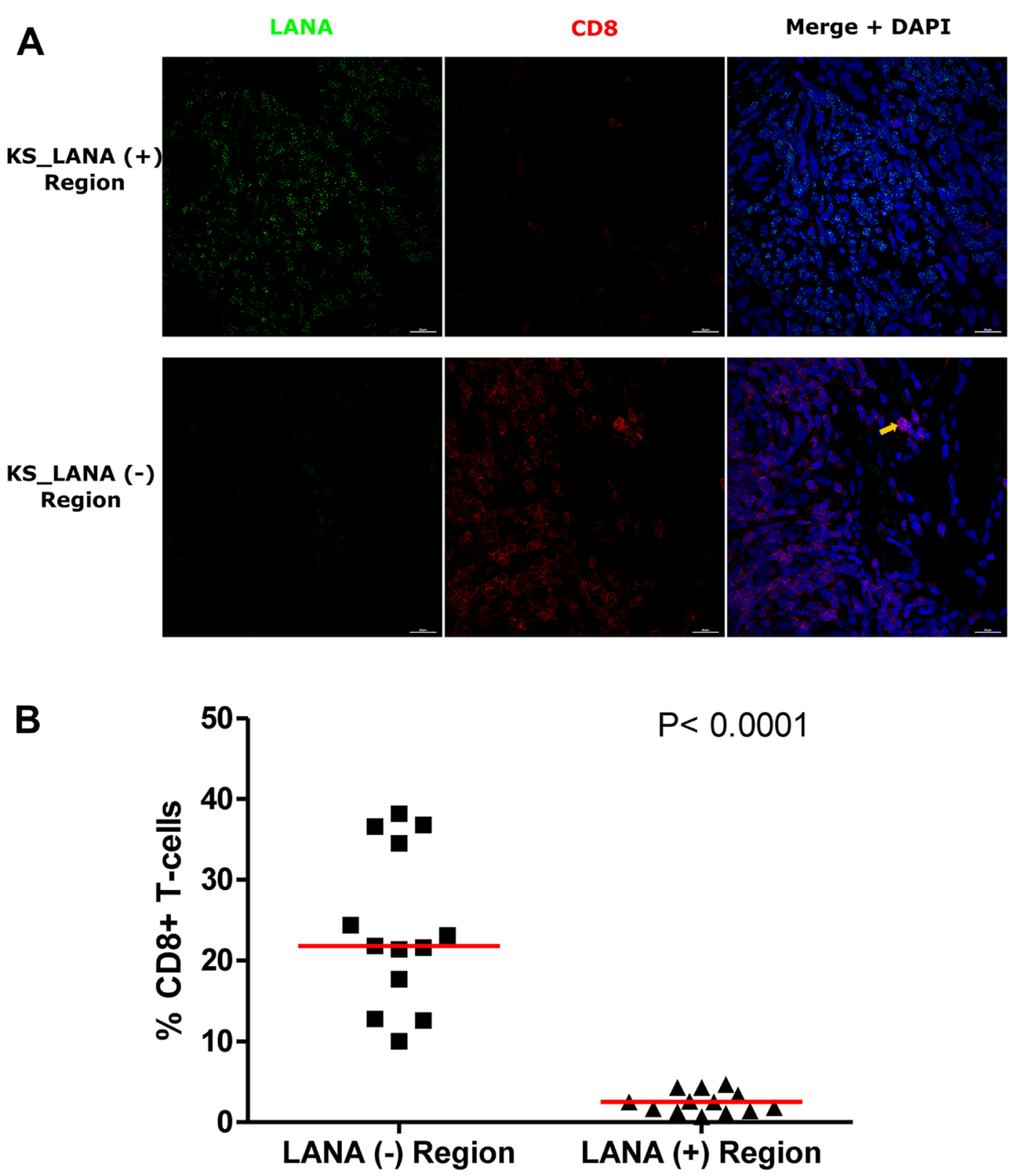

Figure 4: Dual-immunofluorescence staining of Kaposi's Sarcoma-associated Herpesvirus (KSHV) Latency Associated Nuclear Antigen (LANA) protein and $\mathrm{CD8}^{+}$T-cells on Kaposi's Sarcoma (KS) tissues. (A) Representative images are shown ID-C038, Alexa 488 (green) for LANA, Alexa 647 (red) for CD8 and 4',6-Diamino-2-Phenylindole, Dihydrochloride (DAPI) (blue) for nuclei staining. (B) Quantification plot for the percentage CD8 positive cells per field of view. Red horizontal lines indicate median. $(+)-$ Positive and $(-)$ - Negative. Orange arrow - CD8 positive T-cell. 
produced by the tumor cells like IL-10 and TGF- $\beta$, that may impede access to the tumor parenchyma [17, 38].

Like other herpesviruses, $\mathrm{KSHV}$ is known to downregulate MHC class I antigen presentation and T-cell co-stimulation molecules CD86 and ICAM [40, 41]. Through viral encoded K3 and K5, KSHV escapes detection by cytotoxic T-cells and NK cells [42, 43]. vIRF3 also downregulates MHC class II by degrading interferon $-\gamma$ produced by NK cells [44]. It is possible that the lack of T-cell co-localization with KSHV infected cells in KS tumors is a result of KSHV downregulation of interferon responses and antigen presentation. The lack of co-localization could also be due to the lack of T-cell repertoire against $\mathrm{KSHV}$ in the T-cells that chemotactically locate the infected cells in the KS tumor. Studies of circulating T-cell Ag-specific function suggest lack of immunodominance against $\mathrm{KSHV}$ antigens in either KS or asymptomatic patients. Although some T-cell repertoire against KSHV has been reported, most of these responses were weak and variable in different individuals $[45,46]$. It is also possible that the viral peptides presented by Class I on the KS tumors are decoupled from T-cell repertoire recognition, thereby shielding the antigens from the immune systems. This is currently under investigation.

$\mathrm{KSHV}$ is known to induce hypoxic metabolic derangements through HIF-1 expression [47]. The induced metabolic dysfunctions, including Warburglike metabolism, could result in lactate production. The resultant hypoxic and acidic tumor environment could be non-conducive for T-cell infiltration leading to restriction of $\mathrm{CD}^{+}$T-cells access. Although, it appears unlikely given the progressive nature of KS disease, it is also possible that $\mathrm{LANA}^{+}$cells were previously targeted and killed by $\mathrm{CD}^{+} \mathrm{T}$-cells in regions exhibiting enriched T-cells but
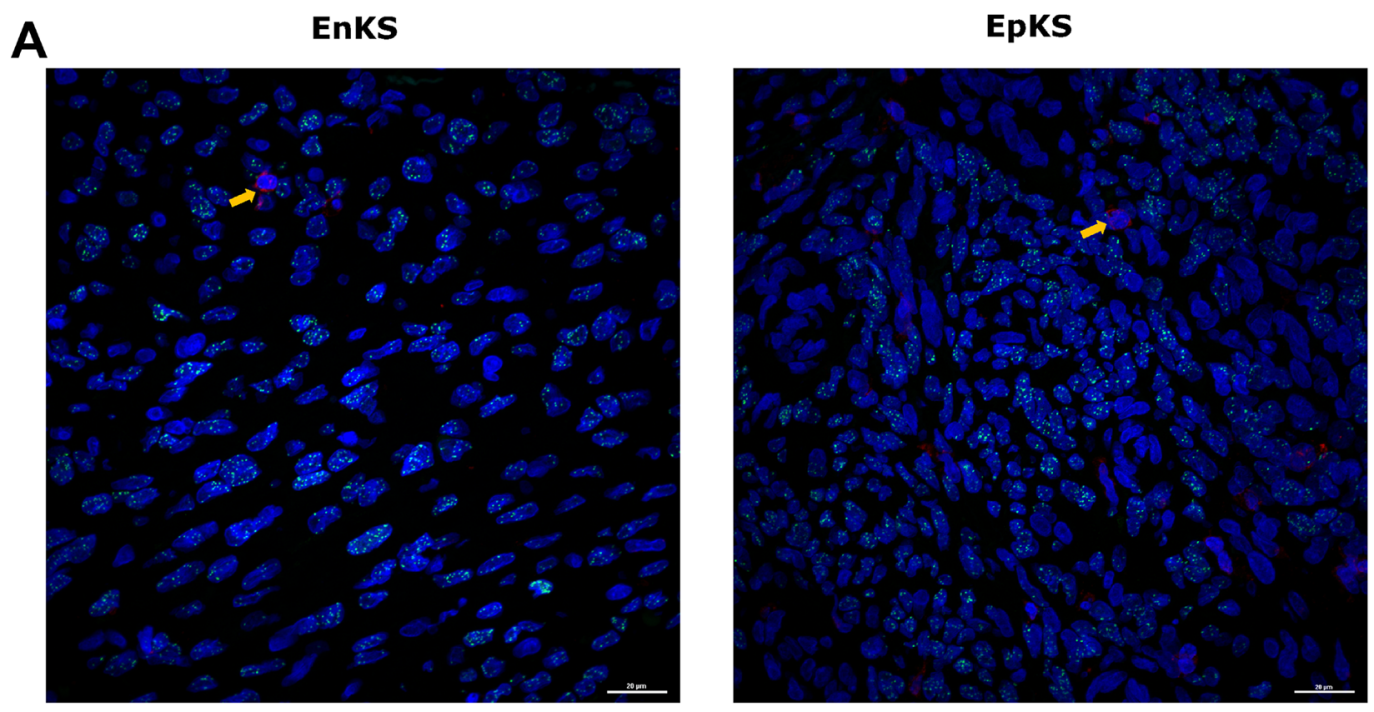

LANA, CD8, DAPI

B

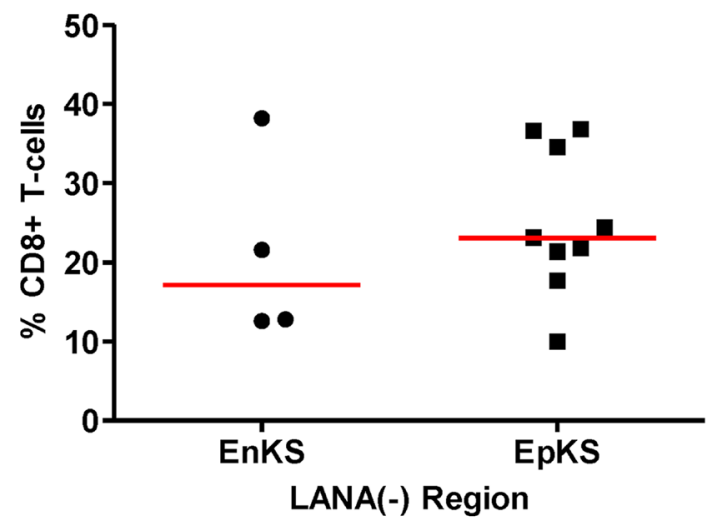

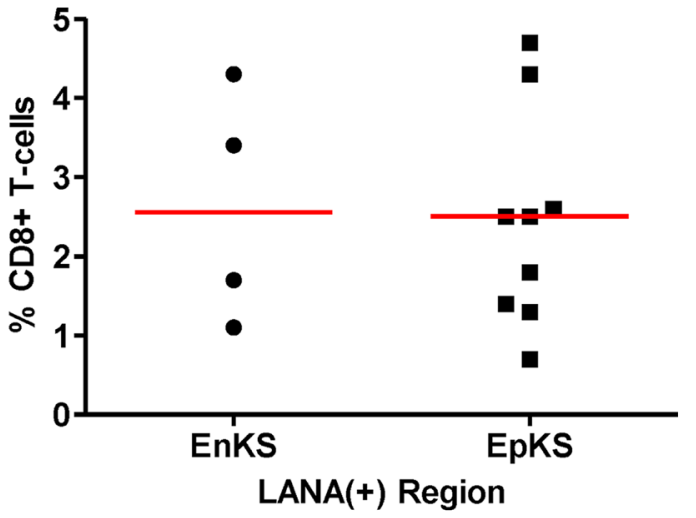

Figure 5: Dual-immunofluorescence staining of Kaposi's Sarcoma-associated Herpesvirus (KSHV) Latency Associated Nuclear Antigen (LANA) protein and $\mathbf{C D 8}^{+}$T-cells on Kaposi's Sarcoma (KS) tissues. (A) Representative images are shown EnKS - ID-C063 and EpKS - ID-C038, Alexa 488 (green) for LANA, Alexa 647 (red) for CD8 and 4',6-Diamino-2-Phenylindole, Dihydrochloride (DAPI) (blue) for nuclei staining. (B) Quantification plot for the percentage CD8 positive cells per field of view. Red horizontal lines indicate median. $(+)$ - Positive and $(-)$ - Negative. EnKS - Endemic KS and EpKS - Epidemic KS. Orange arrows - CD8 positive T-cells. 
devoid of $\mathrm{LANA}^{+}$cells. However, T-cells in these focal areas would have to have become exhausted and unable to proliferate and infiltrate the rest of the tumor [48]. Further studies will be needed to address the immunophenotypes, functionality and KSHV specificity of the CD8 ${ }^{+} \mathrm{T}$-cells and other immune cells from the immune cell infiltrates in KS biopsies. Analysis of MHC class I peptides presented on KS tumors is also important in order to rule out mismatch between T-cell repertoire and Ag presentation repertoire.

Macrophages detect, engulf and destroy invading microorganisms and infected cells [31, 49]. During tumor progression, tumor cells induce maladaptive macrophage phenotypes through metabolic reprogramming [50]. The maladapted macrophages create an immunosuppressive niche leading to tumor progression and therapeutic resistance [51]. Cytokines such as IL-6, IL-10 and TGF- $\beta$ are known to polarize macrophages into the M2 phenotype that is associated with immunosuppression $[9,30,52]$. Interestingly our previous study has shown that IL-6, IL-10, IL-5 and TGF- $\beta$ were elevated in KS patients compared to asymptomatic controls [5]. These cytokines were also associated with increased antibody responses that are not protective against $\mathrm{KS}$ [5]. High levels of macrophages in KS biopsies could be responsible for creating an immunosuppressive niche that restricts CD8+ T-cell infiltration and enhance tumor growth. Overall, it appears that macrophages in KS tumors support KS progression. However, investigation of different macrophage phenotypes and their specific functions in $\mathrm{KS}$ biopsies is needed to understand the role of TIIC in KS.
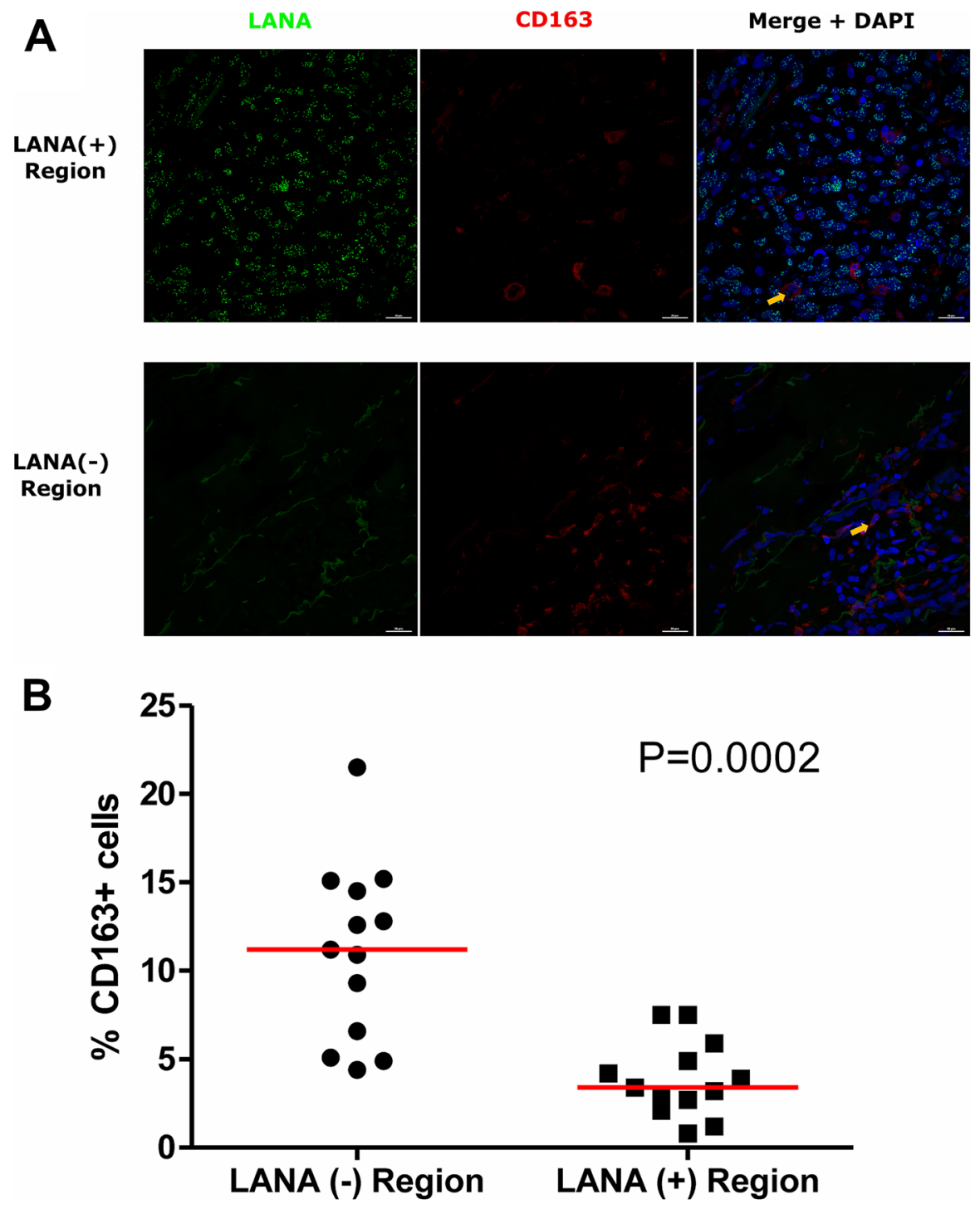

Figure 6: Dual-immunofluorescence staining of Kaposi's Sarcoma-associated Herpesvirus (KSHV) Latency Associated Nuclear Antigen (LANA) protein and CD163 on Kaposi's Sarcoma (KS) tissues. (A) Representative images are shown, Alexa 488 (green) for LANA, Alexa 647 (red) for CD163 and 4',6-Diamino-2-Phenylindole, Dihydrochloride (DAPI) (blue) for nuclei staining ID-C063. (B) Quantification plot for the percentage CD163 positive cells per field of view. Red horizontal lines indicate median. $(+)-$ Positive and (-) - Negative. Orange arrows - CD163 positive cells. 
This study initiated the investigation of TIIC in $\mathrm{KS}$ biopsies in order to understand the role of TIIC in $\mathrm{KS}$. Overall, there is poor immune cell infiltration or co-localization in $\mathrm{LANA}^{+}$regions of KS biopsies. The apparent lack of immune cell co-localization with KSHV infected cells for both EpKS and EnKS suggests that HIV-1 does not significantly influence immune cell infiltration in KS biopsies. However, the size of the cohort, the formalinfixed treatment of the samples as well as the limited tumor and control tissue quantity, have reduced the depth of our investigations. Studies with larger sample sizes patients will be needed to address gaps highlighted in this study. Whether TIICs in KS are functional and match presented peptides in the tumor also need to be further investigated with freshly collected tissue. Correlation between TIIC

A

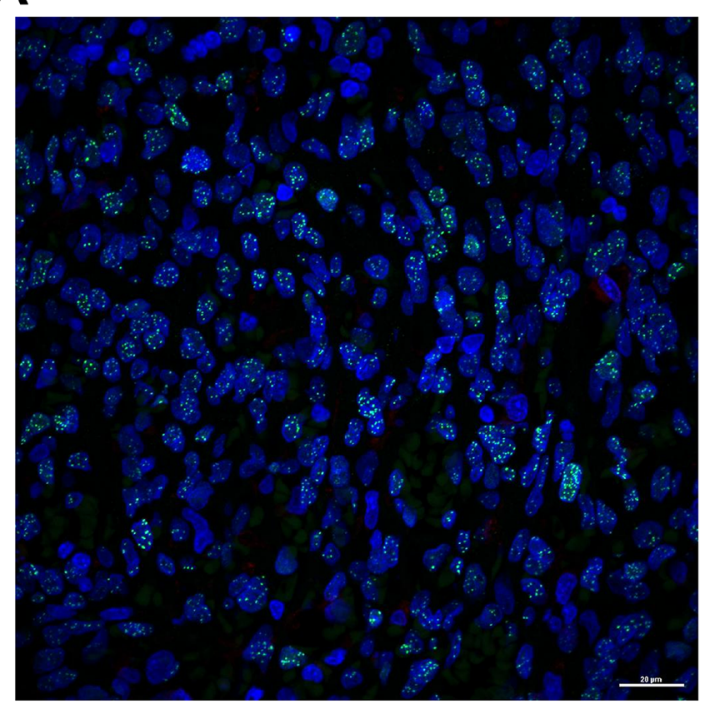

LANA, CD163, DAPI

B

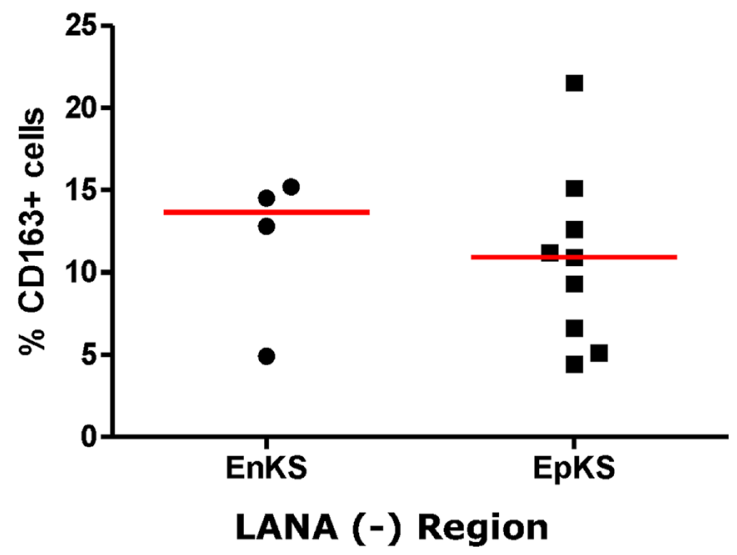

abundance and treatment outcomes of KS could be useful in defining the role of TIIC as a prognostic marker of KS.

\section{MATERIALS AND METHODS}

\section{Study design, subjects and samples}

This cross-sectional study recruited 16 participants (4 EnKS, 9 EpKS KS patients and 3 controls without KS) from Tanzania and Zambia. Participants were of both genders and over 18 years old. Written informed consent was obtained from all study participants. KS was diagnosed by both histology and immunohistochemistry for KSHV latency associated nuclear antigen (LANA). Peripheral blood samples about $10 \mathrm{~mL}$ were collected,

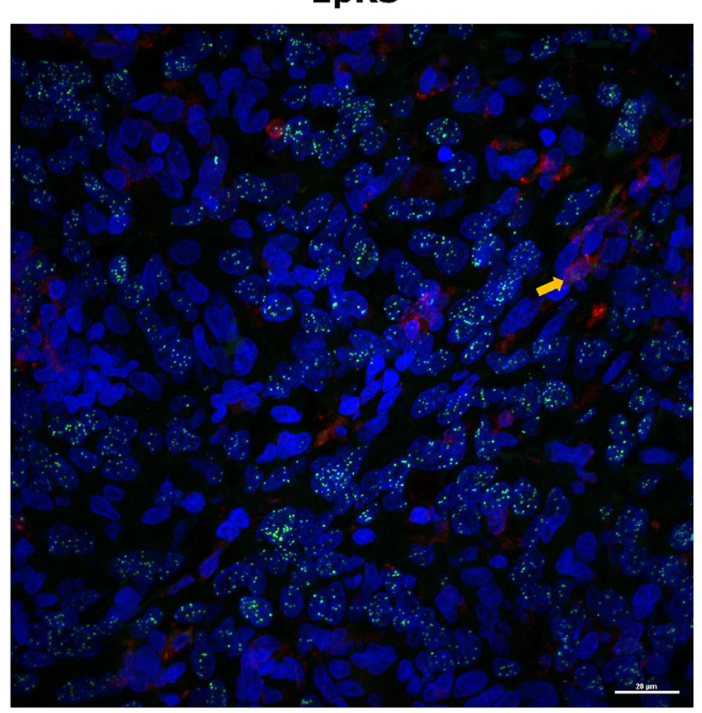

\section{EpKS}

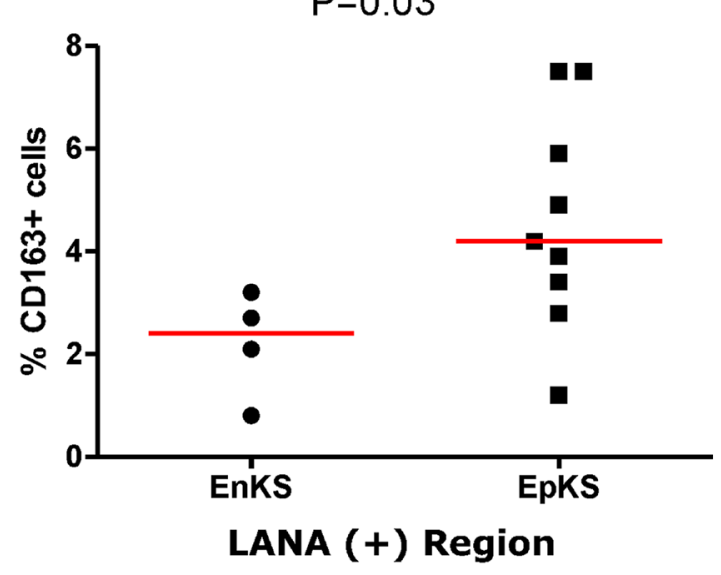

Figure 7: Dual-immunofluorescence staining of Kaposi's Sarcoma-associated Herpesvirus (KSHV) Latency Associated Nuclear Antigen (LANA) protein and CD163 on Kaposi's Sarcoma (KS) tissues. (A) Representative images are shown EnKS - ID-C3096 and EpKS - ID-C038, Alexa 488 (green) for LANA, Alexa 647 (red) for CD163 and 4',6-Diamino-2-Phenylindole, Dihydrochloride (DAPI) (blue) for nuclei staining. (B) Quantification plot for the percentage CD163 positive cells per field of view. Red horizontal lines indicate median. $(+)$ - Positive and $(-)$ - Negative. EnKS - Endemic KS and EpKS - Epidemic KS. Orange arrow - CD163 positive cells. 
plasma was isolated and used for HIV-1 viral load quantification by real-time PCR. A $4 \mathrm{~mm}$ KS biopsy was taken from each subject, fixed in neutral buffered formalin, and processed into a paraffin-embedded block for KS histological diagnosis, LANA IHC and subsequent immunofluorescence staining. This study was approved by the review boards of Tanzania National Institute for Medical Research, Ocean Road Cancer Institute, University of Zambia Biomedical Research Ethics Committee and the University of Nebraska-Lincoln (UNL).

\section{HIV-1 serology and plasma viral load quantification by real-time PCR (RT-PCR)}

HIV-1 serology was determined by point-of-care serology and plasma viral load by quantitative RT-PCR as previously described [5]. Briefly, HIV-1 screening was done using HIV Rapid Test Algorithm in Tanzania or Alere Determine HIV-1/2 Ag/Ab Combo test in Zambia [53]. Viral RNA was extracted from plasma according to the QIAamp viral RNA extraction protocol (Qiagen, Hilden, Germany). The viral copy numbers were then
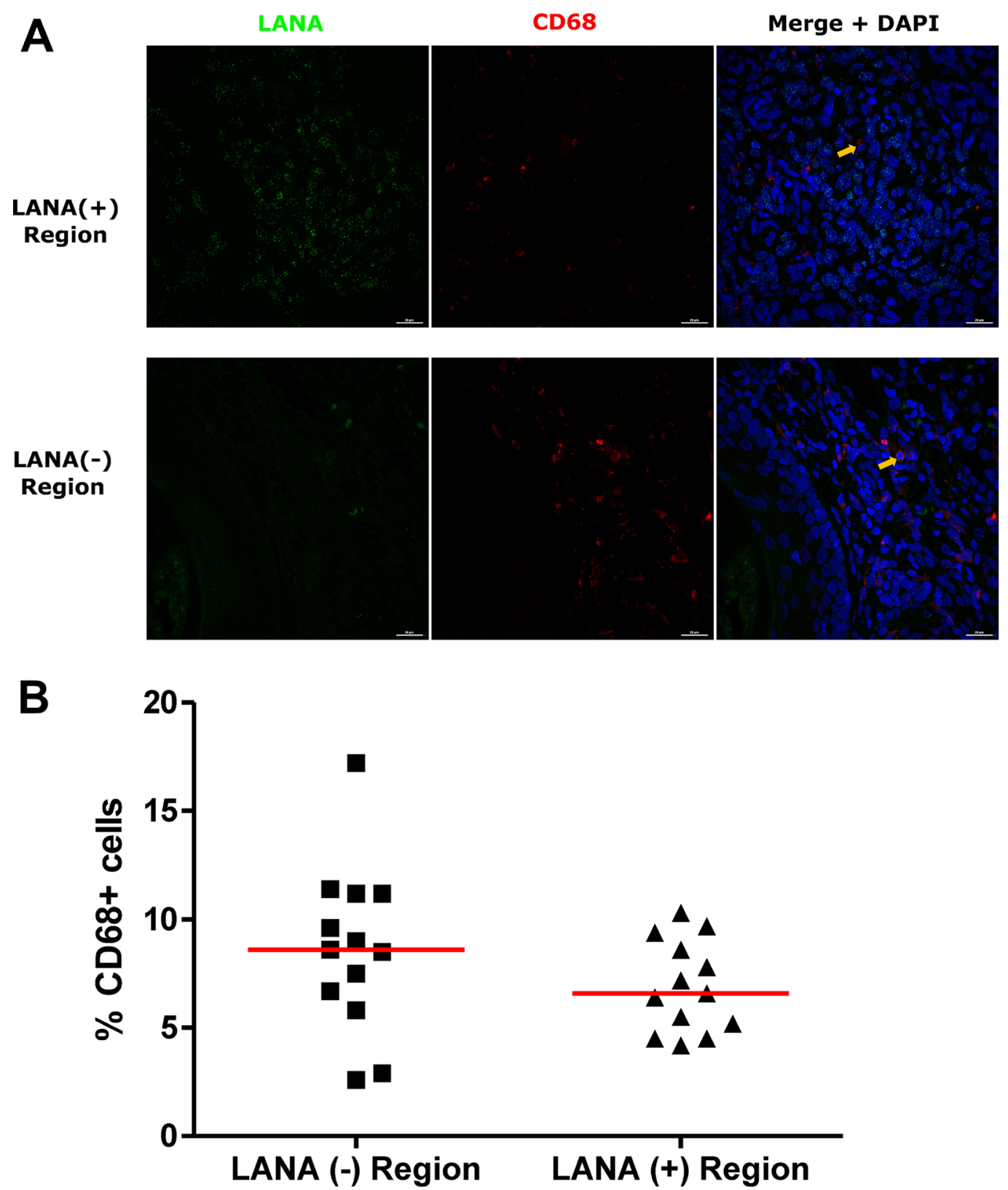

Figure 8: Dual-immunofluorescence staining of Kaposi's Sarcoma-associated Herpesvirus (KSHV) Latency Associated Nuclear Antigen (LANA) protein and CD68 on Kaposi's Sarcoma (KS) tissues. (A) Representative images are shown IDC038, Alexa 488 (green) for LANA, Alexa 647 (red) for CD68 and 4',6-Diamino-2-Phenylindole, Dihydrochloride (DAPI) (blue) for nuclei staining. (B) Quantification plot for the percentage CD68 positive cells per field of view. Red horizontal lines indicate median. $(+)$ - Positive and (-) - Negative. Orange arrows - CD68 positive cells. 
determined using RNA Ultra-Sense One-Step quantitative RT-PCR system (Applied Biosystems, Carlsbad, CA) as previously described with universal HIV LTR primers [54] (forward [5'-GCCTCAATAAAGCTTGCCTTGA-3'] and reverse [5'-GGGCGCCACTGCTAGAGA-3'] and probe [5'-FAM/CCAGAGTCACACAACAGACGGGCACA/BHQ1-3']) under the following conditions: $50^{\circ} \mathrm{C}$ for 15 $\min , 95^{\circ} \mathrm{C}$ for $2 \mathrm{~min}, 40$ cycles of $95^{\circ} \mathrm{C}$ for 15 seconds, and $60^{\circ} \mathrm{C}$ for 30 seconds.

\section{Immunohistochemistry (IHC) and cell quantification}

Adjacent $6 \mu \mathrm{m}$-thick sections of paraffin-embedded $\mathrm{KS}$ tissues were used for IHC, as previously described [55]. Mouse anti-LANA antibody clone NCL-L-HHV8-
LNA (1:100) (Leica Biosystems, Newcastle, UK), antihuman CD8 clone C8/144B (1:100) (Agilent, Santa Clara, CA) or anti-human CD8 clone 4B11 (1:40) (GeneTex, Irvine, CA) were used as primary antibodies. Normal mouse IgG (Dako ×0931, Agilent, Santa Clara, CA) was used as an isotype control at identical concentration.

To quantify the number of positive cells for a specific cell surface marker of interest, all IHC stained slides were digitally scanned on a MoticEasyScan One (Motic, San Antonio, TX) at $40 \times$. On each anti-LANA stained slide, five regions of about $50 \mu \mathrm{m}^{2}$ were selected in regions with high abundance of LANA. The total number of cells and $\mathrm{LANA}^{+}$cells were then quantified using Fiji software (NIH). The same procedure was applied to anti-CD8 stained slides and CD8+ cells were counted. The five high LANA regions were then identified on corresponding CD8 stained
A

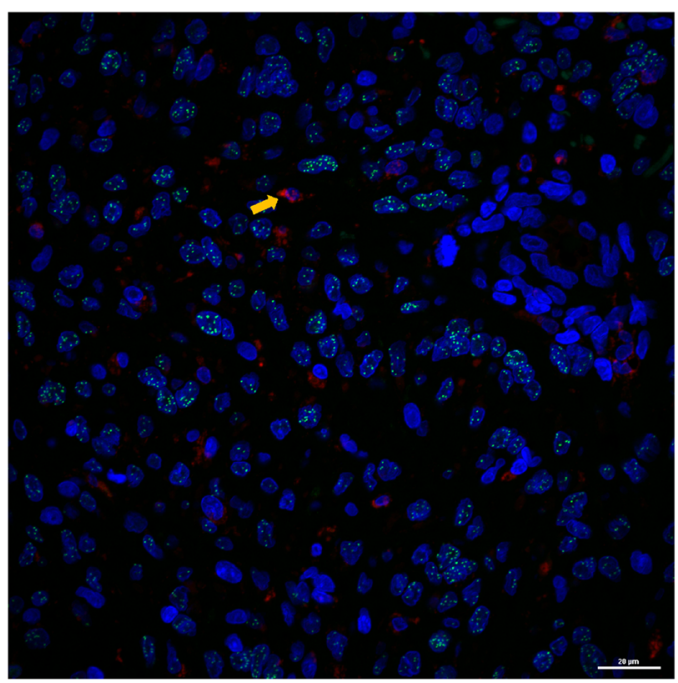

\section{EpKS}

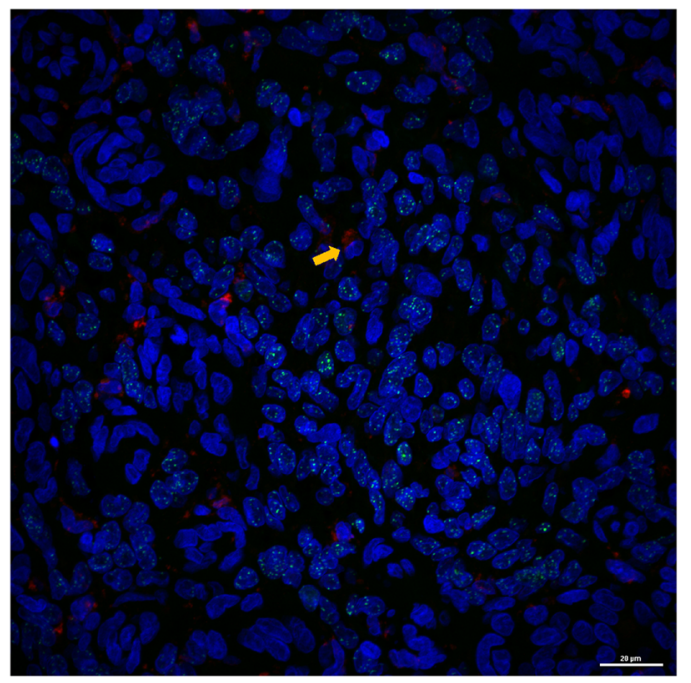

LANA, CD68, DAPI

\section{B}

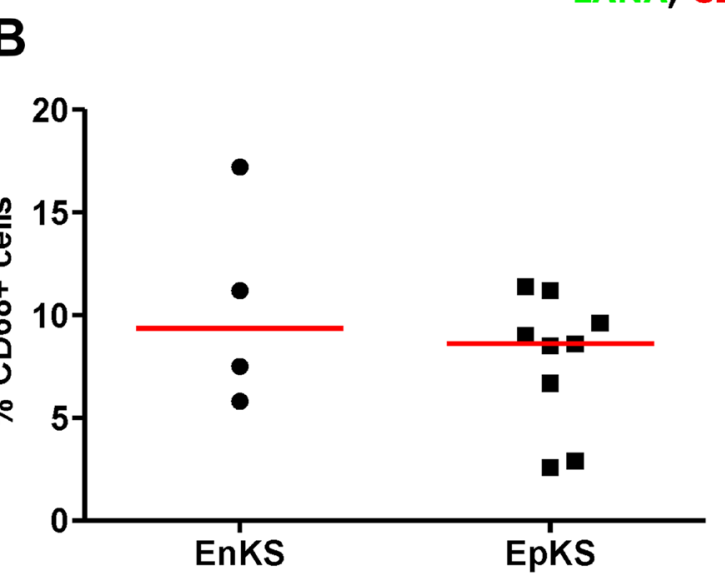

LANA (-) Region

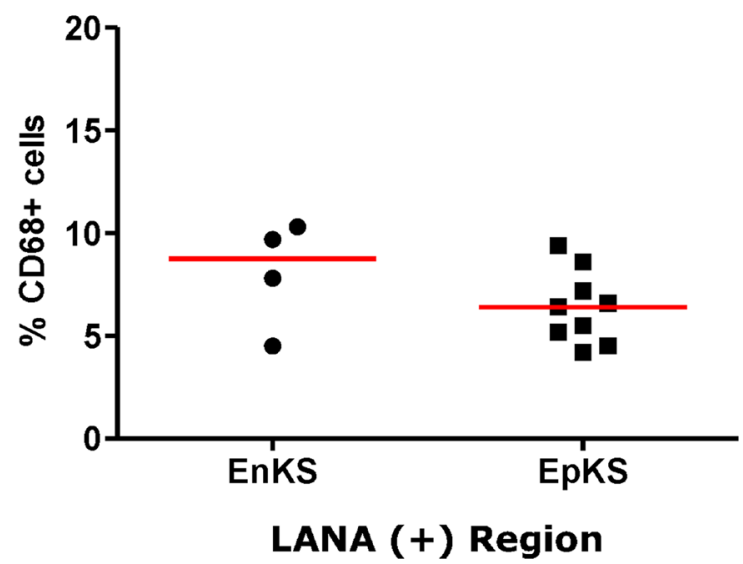

Figure 9: Dual-immunofluorescence staining of Kaposi's Sarcoma-associated Herpesvirus (KSHV) Latency Associated Nuclear Antigen (LANA) protein and CD68 on Kaposi's Sarcoma (KS) tissues. (A) Representative images are shown IDC038, Alexa 488 (green) for LANA, Alexa 647 (red) for CD68 and 4',6-Diamino-2-Phenylindole, Dihydrochloride (DAPI) (blue) for nuclei staining. (B) Quantification plot for the percentage CD68 positive cells per field of view. Red horizontal lines indicate median. $(+)$ - Positive and (-) - Negative. EnKS - Endemic KS and EpKS - Epidemic KS. Orange arrows - CD68 positive cells. 
slides and the total number of cells and $\mathrm{CD} 8^{+} \mathrm{T}$-cells were counted. Reciprocally, the five high CD8+ regions were then identified on corresponding LANA stained slides and the total number of cells and LANA+ cells were counted. Average number of total cells and marker-delineated cells in the five regions were used to calculate proportions of specific markers in an area of high LANA or high $\mathrm{CD}^{+}$ T-cells on adjacent tissue sections. Percentages of specific markers were then calculated and plotted using GraphPad Prism v.5 (GraphPad Software, San Diego, CA).

\section{Dual-Color Immunofluorescence (DIF)}

Adjacent $6 \mu \mathrm{m}$-thick sections of paraffin-embedded $\mathrm{KS}$ tissues were processed following the IHC protocol with modifications. After antigen retrieval, the sections were incubated with $0.3 \mathrm{M}$ glycine for $30 \mathrm{~min}$ at room temperature to minimize tissue auto-fluorescence and Tris- $\mathrm{NaCl}$ blocking buffer (PerkinElmer FP1020, Boston, MA) was used as blocking solution. For DIF, a rat anti-LANA antibody clone LN35 at 1:100 (Abcam, Cambridge, MA) was used together with one of the following primary mouse monoclonal antibodies: anti-CD8 clone C8/144B (1:100), anti-CD4 clone 4B12 (1:100), anti CD34 clone QBEnd10 (1:50), anti-CD68 clone KP1 (1:100), CD19 clone LE-CD19 and anti-CD56 clone 123C3 (1:100) (Agilent, Santa Clara, CA) and antiCD163 clone10D6 (1:100) (Novus Biologicals, Centennial, CO) or goat polyclonal anti-CxCL-9/MIG clone AF392 (R\&D systems, Minneapolis, MN). The primary antibodies were diluted in TNB blocking buffer and incubated at $4^{\circ} \mathrm{C}$ overnight in a humidity chamber. Sections were equilibrated to room temperature, rinsed in $1 \times$ PBS- $0.05 \%$ Tween-20 and then incubated with secondary antibodies Alexa 488-Donkey

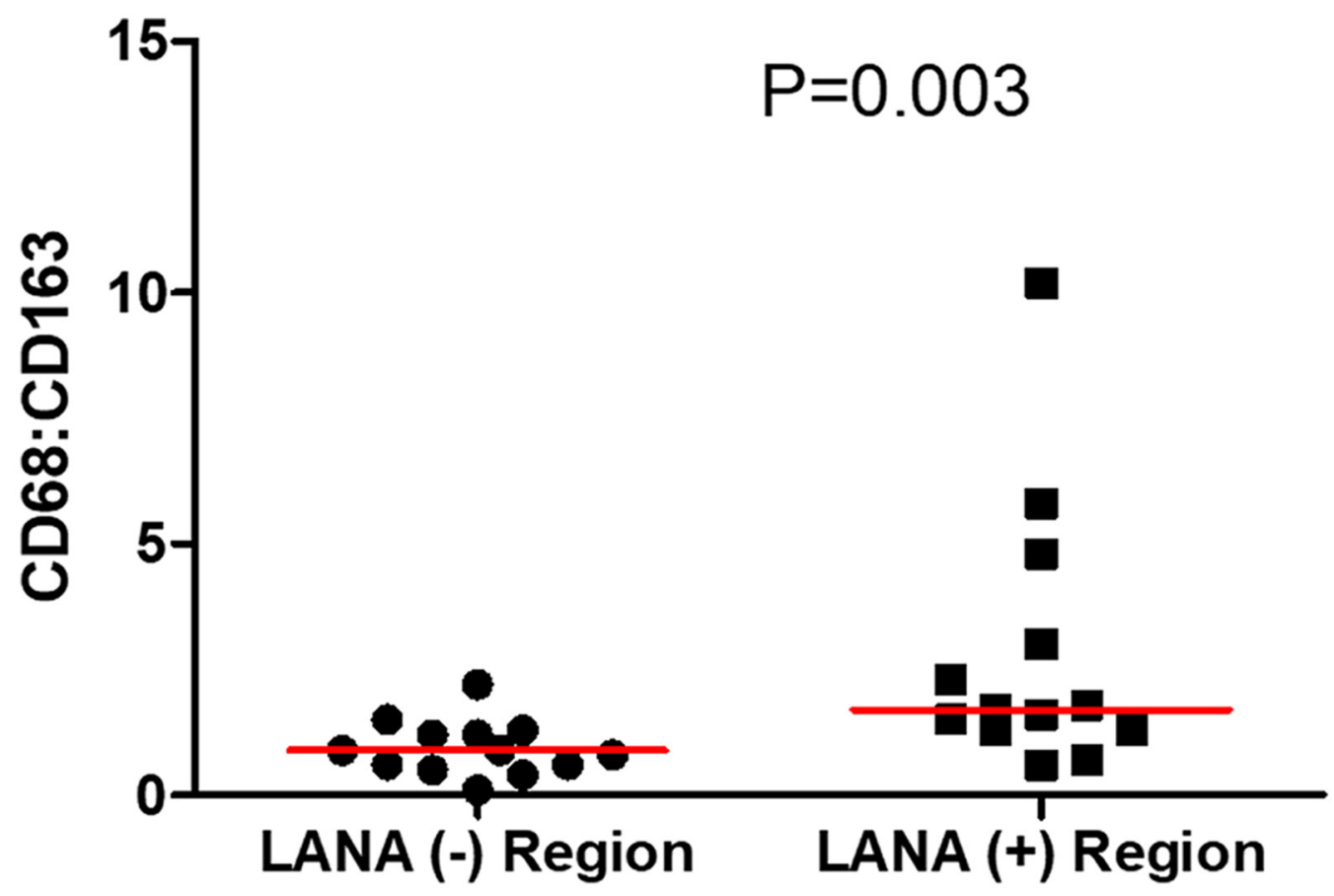
lineage $[22,23]$.

\section{Confocal microscopy and cell quantification}

\section{$\mathrm{P}=0.003$}

anti-rat A21208 together with either Alexa 647-Donkey anti-mouse A31571 (Invitrogen, Eugene, OR) or Alexa 647-Donkey anti-goat A32849, Invitrogen, Rockford IL) for 2 hours at room temperature in a humidity chamber. Nucleus counterstaining was performed with $300 \mathrm{nM}$ 4',6-Diamino-2Phenylindole, Dihydrochloride (DAPI) solution (Invitrogen D1306, Eugene OR) for 30 minutes before mounting coverslip with Fluoro-gel (\# 17985-10, Electron Microscopy Sciences, Hatfield PA). To determine lineage of the KSHV infected cells in the KS tumors, endothelial cell marker CD34 was utilized, consistent with other literature on KS where CD34 has been utilized to demonstrate endothelial

All sections were imaged with Nikon A1R laser scanning confocal system mounted on Nikon Ti2 inverted fluorescence microscope (Nikon Instruments, Melville, NY). Nuclei stained with DAPI were excited at $405 \mathrm{~nm}$ wavelength and emission was collected between 425-475 nm wavelengths. Alexa 488 stained LANA was excited at $488 \mathrm{~nm}$ wavelength and emission was collected between 500-550nm wavelengths. All other surface markers were stained with Alexa 647, and excited at $640 \mathrm{~nm}$ with emission collection between 663-738 nm wavelengths. Images were acquired with NIS elements software (Nikon Instruments, Melville, NY) using sequential scanning (channel series) and Z-stacking (Z-series) of $1 \mu \mathrm{m}$ slices at $60 \times$ magnification. Settings for laser power, detector gain and offset for individual markers were unchanged between slides. LANA positive $(+)$ and negative $(-)$ regions were identified in the same tissue and three representative 
regions with maximum signal (LANA and surface marker) were selected and imaged. Fiji software (NIH) was used on maximum image projections (MaxIP) to quantify the total number of cells, and cells with specific marker enumeration. The average of total number of cells and cells with specific markers in the three regions was used to calculate proportions of specific markers in an area of high LANA and in a region with high $\mathrm{CD} 8^{+} \mathrm{T}$-cells. Percentages of specific markers were then calculated and plotted using GraphPad Prism v.5 (GraphPad Software, San Diego, CA).

\section{Statistical analysis}

Cell surface marker expression was compared between KS tissues and normal skin, between KSHV LANA (+) and (-) regions of the same section or between adjacent sections and between EpKS and EnKS patients. At least 3 sections per tissue were evaluated for all 16 tissue samples. 3 to 5 regions per tissue section were quantified and the average number of cells was used for statistical analysis. All statistical analyses were performed by analysis of variance (ANOVA) and non-parametric Mann-Whitney test using GraphPad Prism v.5 (GraphPad Software, San Diego, CA). All tests were 2 -tailed, and $P$-values $<0.05$ were considered significant.

\section{Abbreviations}

KS: Kaposi's sarcoma; EpKS: Epidemic Kaposi's sarcoma; EnKS: Endemic Kaposi's sarcoma; KSHV: Kaposi's sarcoma associated herpesvirus; TIIC: Tumor infiltrating immune cells; ART: Antiretroviral therapy; HIV-1: Human Immunodeficiency virus type 1; AIDS: Acquired Immunodeficiency syndrome; CxCL-9: Chemokine (CxC motif) ligand 9; LANA: Latency associated nuclear antigen; Treg: Regulatory T-cell; HIV-1: HIV-1 negative; HIV-1 ${ }^{+}$: HIV-1 positive; IHC: Immunohistochemistry; DIF: dual-color immunofluorescence; IL-10: Interleukin-10; IL-6: Interleukin-6; IL-5: Interleukin-5; TGF- $\beta$ : Transforming growth factor $\beta$; DAPI: 4', 6-Diamino-2-Phenylindole, Dihydrochloride; PCR: Polymerase chain reaction; SSA: sub-Saharan Africa.

\section{Author contributions}

CW and JTW conceived and designed the study. JRN, ON and JM performed initial procuring and preparation of the samples. SJL and FYT performed the experiments. SJL, FYT and JK performed sections imaging, quantification and data acquisition. SJL performed statistical analysis and compiled the manuscript. All authors interpreted the results, reviewed the drafts and approved the final version.

\section{ACKNOWLEDGMENTS}

We thank all study participants for agreeing to participate in this study as well as all workers at Ocean Cancer Institute, Tanzania and dermatology and venereology section, University of Zambia for recruiting participants, initial sample procurement and managing data.

\section{CONFLICTS OF INTEREST}

The funders played no role in design of the study, the collection, analysis or interpretation of the data, the writing of the manuscript or the decision to submit the manuscript for publication. We declare that we have no conflict of interest.

\section{FUNDING}

This work was supported by the US National Institute of Health (NIH); National Cancer Institute (NCI); Fogarty International Center (FIC); and National Institute of General Medical Science (NIGMS) (grant numbers 1K43TW011418-01 (SJL), R01CA228178-01 (JTW), U54 CA190155 (CW/JTW), D43 TW010354 and P30 GM103509 (CW), ON is a Fogarty fellow (RO1 CA22817801 (JTW/CW).

\section{REFERENCES}

1. Duman S. Successful treatment of post-transplant Kaposi's sarcoma by reduction of immunosuppression. Nephrol Dial Transplant. 2002; 17: 892-6. https://doi.org/10.1093/ ndt/17.5.892. [PubMed]

2. Franceschi S, Maso LD, Rickenbach M, Polesel J, Hirschel B, Cavassini M, Bordoni A, Elzi L, Ess S, Jundt G, Mueller N, Clifford GM, Battegay M, et al. Kaposi sarcoma incidence in the Swiss HIV Cohort Study before and after highly active antiretroviral therapy. Br J Cancer. 2008; 99:800-804. https://doi.org/10.1038/sj.bjc.6604520. [PubMed]

3. Cook-Mozaffari P, Newton R, Beral V, Burkitt DP. The geographical distribution of Kaposi's sarcoma and of lymphomas in Africa before the AIDS epidemic. Br J Cancer. 1998; 78:1521-1528. https://doi.org/10.1038/ bjc.1998.717. [PubMed]

4. Labo N, Marshall V, Miley W, Davis E, McCann B, Stolka KB, Ndom P, Hemingway-Foday JJ, Abassora M, Newton R, Smith JS, Whitby D. Mutual detection of Kaposi's sarcoma-associated herpesvirus and Epstein-Barr virus in blood and saliva of Cameroonians with and without Kaposi's sarcoma. Int J Cancer. 2019; 145:2468-77. https:// doi.org/10.1002/ijc.32546. [PubMed]

5. Lidenge SJ, Tso FY, Ngalamika O, Ngowi JR, Mortazavi Y, Kwon EH, Shea DM, Minhas V, Mwaiselage J, Wood C, West JT. Similar immunological profiles between 
African endemic and human immunodeficiency virus type 1-associated epidemic Kaposi Sarcoma (KS) patients reveal the primary role of KS-associated herpesvirus in $\mathrm{KS}$ pathogenesis. J Infect Dis. 2019; 219:1318-28. https://doi. org/10.1093/infdis/jiy654. [PubMed]

6. Odunsi K, Old LJ. Tumor infiltrating lymphocytes: indicators of tumor-related immune responses. Cancer Immun. 2007; 7:3. [PubMed]

7. Chen J, He Q, Liu J, Xiao Y, Xiao C, Chen K, Xie D, Zhang X. CD8+ tumor-infiltrating lymphocytes as a novel prognostic biomarker in lung sarcomatoid carcinoma, a rare subtype of lung cancer. Cancer Manag Res. 2018; 10:35053511. https://doi.org/10.2147/CMAR.S169074. [PubMed]

8. Fu Q, Chen N, Ge C, Li R, Li Z, Zeng B, Li C, Wang Y, Xue Y, Song X, Li H, Li G. Prognostic value of tumor-infiltrating lymphocytes in melanoma: a systematic review and metaanalysis. Oncoimmunology. 2019; 8:1593806. https://doi.or g/10.1080/2162402X.2019.1593806. [PubMed]

9. Barros MH, Hauck F, Dreyer JH, Kempkes B, Niedobitek G. Macrophage Polarisation: an Immunohistochemical Approach for Identifying M1 and M2 Macrophages. PLoS One. 2013; 8:e80908. https://doi.org/10.1371/journal. pone.0080908. [ [PubMed]

10. Yang L, Wang F, Wang L, Huang L, Wang J, Zhang B, Zhang Y. CD163+ tumor-associated macrophage is a prognostic biomarker and is associated with therapeutic effect on malignant pleural effusion of lung cancer patients. Oncotarget. 2015; 6: 10592-603. https://doi.org/10.18632/ oncotarget.3547. [PubMed]

11. Kubota K, Moriyama M, Furukawa S, Rafiul HASM, Maruse Y, Jinno T, Tanaka A, Ohta M, Ishiguro N, Yamauchi M, Sakamoto M, Maehara T, Hayashida JN, et al. CD163+CD204+ tumor-associated macrophages contribute to $\mathrm{T}$ cell regulation via interleukin-10 and $\mathrm{PD}-\mathrm{L} 1$ production in oral squamous cell carcinoma. Sci Rep. 2017; 7:1755. https://doi.org/10.1038/s41598-017-01661-z. [PubMed]

12. Mills CD, Lenz LL, Harris RA. A breakthrough: Macrophage-directed cancer immunotherapy. Cancer Research. 2016; 76:513-516. https://doi.org/10.1158/00085472.CAN-15-1737. [PubMed]

13. Stevanović S, Draper LM, Langhan MM, Campbell TE, Kwong ML, Wunderlich JR, Dudley ME, Yang JC, Sherry RM, Kammula US, Restifo NP, Rosenberg SA, Hinrichs CS. Complete regression of metastatic cervical cancer after treatment with human papillomavirus-targeted tumorinfiltrating T cells. J Clin Oncol. 2015; 33:1543-1550. https://doi.org/10.1200/JCO.2014.58.9093. [PubMed]

14. Mullinax JE, Hall M, Prabhakaran S, Weber J, Khushalani N, Eroglu Z, Brohl AS, Markowitz J, Royster E, Richards A, Stark V, Zager JS, Kelley L, et al. Combination of ipilimumab and adoptive cell therapy with tumor-infiltrating lymphocytes for patients with metastatic melanoma. Front Oncol. 2018; 8:44. https://doi.org/10.3389/fonc.2018.00044. [PubMed]
15. Yao W, He J, Yang Y, Wang J, Qian Y, Yang T, Ji L. The Prognostic Value of Tumor-infiltrating Lymphocytes in Hepatocellular Carcinoma: a Systematic Review and Metaanalysis. Sci Rep. 2017; 7: 7525. https://doi.org/10.1038/ s41598-017-08128-1. [PubMed]

16. Antohe M, Nedelcu R, Nichita L, Popp C, Cioplea M, Brinzea A, Hodorogea A, Calinescu A, Balaban M, Ion D, Diaconu C, Bleotu C, Pirici D, et al. Tumor infiltrating lymphocytes: The regulator of melanoma evolution (Review). Oncol Lett. 2019; 17: 4155-61. https://doi. org/10.3892/ol.2019.9940. [PubMed]

17. Tso FY, Kossenkov AV, Lidenge SJ, Ngalamika O, Ngowi JR, Mwaiselage J, Wickramasinghe J, Kwon EH, West JT, Lieberman PM, Wood C. RNA-Seq of Kaposi's sarcoma reveals alterations in glucose and lipid metabolism. PLoS Pathog. 2018; 14:e1006844. https://doi.org/10.1371/journal. ppat.1006844. [PubMed]

18. Bromley SK, Mempel TR, Luster AD. Orchestrating the orchestrators: Chemokines in control of $\mathrm{T}$ cell traffic. Nat Immunol. 2008; 9:970-980. https://doi.org/10.1038/ ni.f.213. [PubMed]

19. Chalya PL, Mbunda F, Rambau PF, Jaka H, Masalu N, Mirambo M, Mushi MF, Kalluvya SE. Kaposi's sarcoma: a 10-year experience with 248 patients at a single tertiary care hospital in Tanzania. BMC Res Notes. 2015; 8:440. https:// doi.org/10.1186/s13104-015-1348-9. [PubMed]

20. Garrigues HJ, Howard K, Barcy S, Ikoma M, Moses AV, Deutsch GH, Wu D, Ueda K, Rose TM. Full-Length Isoforms of Kaposi's Sarcoma-Associated Herpesvirus LatencyAssociated Nuclear Antigen Accumulate in the Cytoplasm of Cells Undergoing the Lytic Cycle of Replication. J Virol. 2017; 91. https://doi.org/10.1128/jvi.01532-17. [PubMed]

21. Uppal T, Banerjee S, Sun Z, Verma SC, Robertson ES. KSHV LANA - The Master Regulator of KSHV Latency. Viruses. 2014; 6:4691-4998. https://doi.org/10.3390/ v6124961. [PubMed]

22. Cancian L, Hansen A, Boshoff C. Cellular origin of Kaposi's sarcoma and Kaposi's sarcoma-associated herpesvirus-induced cell reprogramming. Trends Cell Biol. 2013; 23:421-32. https://doi.org/10.1016/j.tcb.2013.04.001. [PubMed]

23. Li Y, Zhong C, Liu D, Yu W, Chen W, Wang Y, Shi S, Yuan Y. Evidence For Kaposi's Sarcoma Originating From Mesenchymal Stem Cell Through KSHV-induced Mesenchymal-to-Endothelial Transition. Cancer Res. 2018; 78:230-245. https://doi.org/10.1158/0008-5472.CAN-171961. [PubMed]

24. Muniraju M, Mutsvunguma LZ, Foley J, Escalante GM, Rodriguez E, Nabiee R, Totonchy J, Mulama DH, Nyagol J, Wussow F, Barasa AK, Brehm M, Ogembo JG. Kaposi Sarcoma-Associated Herpesvirus Glycoprotein H Is Indispensable for Infection of Epithelial, Endothelial, and Fibroblast Cell Types. J Virol. 2019; 93. https://doi. org/10.1128/jvi.00630-19. [PubMed] 
25. Rappocciolo G, Jais M, Piazza PA, DeLucia DC, Jenkins FJ, Rinaldo CR. Human Herpesvirus 8 Infects and Replicates in Langerhans Cells and Interstitial Dermal Dendritic Cells and Impairs Their Function. J Virol. 2017; 91. https://doi. org/10.1128/jvi.00909-17. [PubMed]

26. Faure A, Hayes M, Sugden B. How Kaposi's sarcomaassociated herpesvirus stably transforms peripheral B cells towards lymphomagenesis. Proc Natl Acad Sci U S A. 2019; 116:16519-28. https://doi.org/10.1073/pnas.1905025116. [PubMed]

27. Ochiai E, Sa Q, Brogli M, Kudo T, Wang X, Dubey JP, Suzuki Y. CXCL9 is important for recruiting immune T cells into the brain and inducing an accumulation of the $\mathrm{T}$ cells to the areas of tachyzoite proliferation to prevent reactivation of chronic cerebral infection with Toxoplasma gondii. Am J Pathol. 2015; 185:314-24. https://doi. org/10.1016/j.ajpath.2014.10.003. [PubMed]

28. Tokunaga R, Zhang W, Naseem M, Puccini A, Berger MD, Soni S, McSkane M, Baba H, Lenz HJ. CXCL9, CXCL10, CXCL11/CXCR3 axis for immune activation - A target for novel cancer therapy. Cancer Treatment Reviews. 2018; 63:40 47. https://doi.org/10.1016/j.ctrv.2017.11.007. [PubMed]

29. Arango Duque G, Descoteaux A. Macrophage cytokines: involvement in immunity and infectious diseases. Front Immunol. 2014; 5:491. https://doi.org/10.3389/ fimmu.2014.00491. [ubMed]

30. Nielsen SR, Schmid MC. Macrophages as Key Drivers of Cancer Progression and Metastasis. Mediators of Inflammation. 2017; 2017:9624760. https://doi.org/10.1155/2017/9624760. [PubMed]

31. Hu K, Jin Y, Chroneos Z, Han X, Liu H, Lin L. Macrophage functions and regulation: Roles in diseases and implications in therapeutics. Journal of Immunology Research. 2018; 2018:7590350. https://doi.org/10.1155/2018/7590350. [PubMed]

32. El-Kenawi A. With macrophages, tumors won't go hungry. Sci Transl Med. 2019; 11:eaax1722. https://doi.org/10.1126/ scitranslmed.aax 1722 .

33. Cheng Z, Zhang D, Gong B, Wang P, Liu F. CD163 as a novel target gene of STAT3 is a potential therapeutic target for gastric cancer. Oncotarget. 2017; 8:87244-87262. https://doi.org/10.18632/oncotarget.20244. [PubMed]

34. Tippett E, Cheng WJ, Westhorpe C, Cameron PU, Brew BJ, Lewin SR, Jaworowski A, Crowe SM. Differential Expression of CD163 on Monocyte Subsets in Healthy and HIV-1 Infected Individuals. PLoS One. 2011; 6:e19968. https://doi.org/10.1371/journal.pone.0019968. [PubMed]

35. D'Antoni ML, Byron MM, Chan P, Sailasuta N, Sacdalan C, Sithinamsuwan P, Tipsuk S, Pinyakorn S, Kroon E, Slike BM, Krebs SJ, Khadka VS, Chalermchai T, et al. Normalization of Soluble CD163 Levels After Institution of Antiretroviral Therapy During Acute HIV Infection Tracks with Fewer Neurological Abnormalities. J Infect Dis. 2018; 218:1453-63. https://doi.org/10.1093/infdis/jiy337. [PubMed]
36. Durgeau A, Virk Y, Corgnac S, Mami-Chouaib F. Recent advances in targeting CD8 T-cell immunity for more effective cancer immunotherapy. Frontiers in Immunology. 2018; 9:14. https://doi.org/10.3389/fimmu.2018.00014. [PubMed]

37. Farhood B, Najafi M, Mortezaee K. CD8+ cytotoxic T lymphocytes in cancer immunotherapy: A review. Journal of Cellular Physiology. 2019; 234:8509-8521. https://doi. org/10.1002/jcp.27782. [PubMed]

38. Maimela NR, Liu S, Zhang Y. Fates of CD8+ T cells in Tumor Microenvironment. Computational and Structural Biotechnology Journal. 2019; 17:1-13. https://doi. org/10.1016/j.csbj.2018.11.004. [PubMed]

39. Lepone LM, Rappocciolo G, Piazza PA, Campbell DM, Jenkins FJ, Rinaldo CR. Regulatory T Cell Effect on CD8 $+\mathrm{T}$ Cell Responses to Human Herpesvirus 8 Infection and Development of Kaposi's Sarcoma. AIDS Res Hum Retroviruses. 2017; 33:668-674. https://doi.org/10.1089/ aid.2016.0155. [PubMed]

40. Coscoy L, Sanchez DJ, Ganem D. A novel class of herpesvirus-encoded membrane-bound E3 ubiquitin ligases regulates endocytosis of proteins involved in immune recognition. J Cell Biol. 2001; 155: 1265-73. https://doi. org/10.1083/jcb.200111010. [PubMed]

41. Lehner PJ, Hoer S, Dodd RB, Duncan LM. Downregulation of cell surface receptors by the K3 family of viral and cellular ubiquitin E3 ligases. Immunological Reviews. 2005; 207:112-25. https://doi.org/10.1111/j.01052896.2005.00314.x. [PubMed]

42. Nathan JA, Lehner PJ. The trafficking and regulation of membrane receptors by the RING-CH ubiquitin E3 ligases. Experimental Cell Research. 2009; 315:1593-600. https:// doi.org/10.1016/j.yexcr.2008.10.026. [PubMed]

43. Manes TD, Hoer S, Muller WA, Lehner PJ, Pober JS. Kaposi's Sarcoma-Associated Herpesvirus K3 and K5 Proteins Block Distinct Steps in Transendothelial Migration of Effector Memory CD4+ T Cells by Targeting Different Endothelial Proteins. J Immunol. 2010; 184:5186-92. https://doi.org/10.4049/jimmunol.0902938. [PubMed]

44. Schmidt K, Wies E, Neipel F. Kaposi's sarcoma-associated herpesvirus viral interferon regulatory factor 3 inhibits gamma interferon and major histocompatibility complex class II expression. J Virol. 2011; 85: 4530-7. https://doi. org/10.1128/JVI.02123-10. [PubMed]

45. Robey RC, Mletzko S, Gotch FM. The T-cell immune response against Kaposi's sarcoma-associated herpesvirus. Adv Virol. 2010; 2010:1-9. $\quad$ https://doi.org/10.1155/2010/340356. [PubMed]

46. Roshan R, Labo N, Trivett M, Miley W, Marshall V, Coren L, Cornejo Castro EM, Perez H, Holdridge B, Davis E, Matus-Nicodemos R, Ayala VI, Sowder R, et al. T-cell responses to KSHV infection: a systematic approach. Oncotarget. 2017; 8:109402-16. https://doi.org/10.18632/ oncotarget.22683. [PubMed] 
47. Ma T, Patel H, Babapoor-Farrokhran S, Franklin R, Semenza GL, Sodhi A, Montaner S. KSHV induces aerobic glycolysis and angiogenesis through HIF-1-dependent upregulation of pyruvate kinase 2 in Kaposi's sarcoma. Angiogenesis. 2015; 18:477-488. https://doi.org/10.1007/s10456-015-9475-4. [PubMed]

48. He QF, Xu Y, Li J, Huang ZM, Li XH, Wang X. CD81 T-cell exhaustion in cancer: Mechanisms and new area for cancer immunotherapy. Brief Funct Genomics. 2019; 18:99-106. https://doi.org/10.1093/bfgp/ely006. [PubMed]

49. Gordon S, Plüddemann A. Tissue macrophages: Heterogeneity and functions. BMC Biology. 2017; 15:53. https://doi.org/10.1186/s12915-017-0392-4. [PubMed]

50. Halbrook CJ, Pontious C, Kovalenko I, Lapienyte L, Dreyer S, Lee HJ, Thurston G, Zhang Y, Lazarus J, Sajjakulnukit P, Hong HS, Kremer DM, Nelson BS, et al. MacrophageReleased Pyrimidines Inhibit Gemcitabine Therapy in Pancreatic Cancer. Cell Metab. 2019; 29:1390-1399.e6. https://doi.org/10.1016/j.cmet.2019.02.001. [PubMed]

51. Goossens P, Rodriguez-Vita J, Etzerodt A, Masse M, Rastoin O, Gouirand V, Ulas T, Papantonopoulou O, Van Eck M, Auphan-Anezin N, Bebien M, Verthuy C, Vu Manh TP, et al. Membrane Cholesterol Efflux Drives TumorAssociated Macrophage Reprogramming and Tumor Progression. Cell Metab. 2019; 29:1376-1389.e4. https:// doi.org/10.1016/j.cmet.2019.02.016. [PubMed]
52. Wang J, Li D, Cang H, Guo B. Crosstalk between cancer and immune cells: Role of tumor-associated macrophages in the tumor microenvironment. Cancer Medicine. 2019; 8:4709-4721. https://doi.org/10.1002/cam4.2327. [PubMed]

53. United Republic of Tanzania, Ministry of Health and Social Welfare NACP. Guidelines on HIV Testing and Counseling in Clinical Settings. 2007. Available from http://www. who.int/hiv/topics/vet/TZ PITC-Guidelines final edit July2007.pdf.

54. Tso FY, Kang G, Kwon EH, Julius P, Li Q, West JT, Wood C. Brain is a potential sanctuary for subtype C HIV-1 irrespective of ART treatment outcome. PLoS One. 2018; 13:e0201325. https://doi.org/10.1371/journal. pone.0201325. [PubMed]

55. Tso FY, Sawyer A, Kwon EH, Mudenda V, Langford D, Zhou Y, West J, Wood C. Kaposi's Sarcoma-Associated Herpesvirus Infection of Neurons in HIV-Positive Patients. J Infect Dis. 2017; 215:1898-907. https://doi.org/10.1093/ infdis/jiw545. [PubMed] 